\title{
Heparin- and Rosuvastatin- loaded Poly(L-lactide- co-caprolactone) Nanofiber Aneurysm Covered Stent Inhibits Inflammatory Smooth Muscle Cell in Reducing in-stent Stenosis and Thrombosis
}

\section{Yingjun Liu}

Fudan University Huashan Hospital Department of Neurosurgery

Peixi Liu

Fudan University Huashan Hospital Department of Neurosurgery

\section{Yaying Song}

Shanghai Jiao Tong University School of Medicine Affiliated Renji Hospital

\section{Sichen Li}

Fudan University Huashan Hospital Department of Neurosurgery

\section{Yuan Shi}

Fudan University Huashan Hospital Department of Neurosurgery

\section{Kai Quan}

Fudan University Huashan Hospital Department of Neurosurgery

Guo Yu

Fudan University Huashan Hospital Department of Neurosurgery

\section{Peiliang Li}

Fudan University Huashan Hospital Department of Neurosurgery

\section{Qingzhu An}

Fudan University Huashan Hospital Department of Neurosurgery

Wei Zhu ( $\nabla$ drzhuwei@fudan.edu.cn )

Fudan University Huashan Hospital Department of Neurosurgery https://orcid.org/0000-0001-71907476

\section{Research Article}

Keywords: Rosuvastatin, intracranial aneurysm, late thrombosis, long-term arterial stenosis, nanofibercovered stent

Posted Date: March 2nd, 2021

DOI: https://doi.org/10.21203/rs.3.rs-255688/v1 
License: (c) (i) This work is licensed under a Creative Commons Attribution 4.0 International License. Read Full License 


\section{Abstract}

Background: Endovascular covered-stent has unique advantages in treating complex intracranial aneurysms. However, in-stent stenosis and late thrombosis have become the main factors affecting the efficacy of covered-stent treatment. Smooth-muscle-cell phenotypic modulation plays an important role in late in-stent stenosis and thrombosis. Thus, covered stents loaded with drugs that can inhibit smoothmuscle-cell phenotypic modulation may lower the incidence of long-term complications.

Methods: Nanofiber covered stents were prepared using coaxial electrospinning. A rabbit-carotid-artery aneurysm model was established and treated with covered stents. Angiography and histology were performed to evaluate the therapeutic efficacy and incidence rate of in-stent stenosis and thrombosis. Phenotype, function, and inflammatory factors of smooth-muscle cells were studied to explore the mechanism of rosuvastatin in smooth-muscle cells.

Result: Heparin-rosuvastatin-loaded nanofiber scaffolds inhibited the proliferation of synthetic smoothmuscle cells. Heparin-rosuvastatin-loaded nanofiber covered stent effectively treated aneurysms without showing any notable in-stent stenosis. In vitro experiments showed that rosuvastatin could inhibit the smooth muscle cell phenotypic modulation of platelet-derived growth factor-BB induction. The inflammatory cytokines secretion and cell viability were inhibited after rosuvastatin treatment.

Conclusion: Rosuvastatin could inhibit the abnormal proliferation of synthetic smooth-muscle cells. Heparin-rosuvastatin-loaded covered stents could reduce the incidence of stenosis and late thrombosis and improve the healing rates of stents used for aneurysm treatment.

\section{Background}

Intracranial aneurysm (IA) is a cerebrovascular disease with an annual incidence of approximately $3 \%$ (1) and an annual rupture rate of approximately $1.4 \%$ (2). The mortality rate after aneurysm rupture can be as high as $60 \%$ (3). The International Subarachnoid Aneurysm Trial (ISAT) $(4,5)$ and the International Study of Unruptured Intracranial Aneurysms (ISUIA) $(6,7)$ proved that interventional therapy results in a lower mortality rate than a craniotomy (8). Although coil implantation is the basic method of IA treatment (9), it is unsuitable for complex IAs. Typical stents implanted to treat IAs currently include flow-diverter devices $(10)$ and the Willis covered stent $(11,12)$. Long-term stenosis and late thrombosis can substantially affect the therapeutic effect of the stent. Although first-generation drug-eluting stents (DES) appeared to improve short-term in-stent stenosis, the ability of drugs to inhibit cell proliferation may cause delayed reendothelialization. Second-generation DES employed improved drug loadings to unilaterally inhibit the abnormal proliferation of smooth-muscle cells (SMCs) without affecting endothelial-cell (EC) functions.

DES polymers such as polytetrafluoroethylene (PTFE) and polyethylene terephthalate (PET) can aggravate the human body's natural inflammatory immune response (13) by promoting the activation of inflammatory SMCs, thereby leading to in-stent stenosis. Although PTFE shows excellent performance in 
wide arteries, it is unsuitable for arteries narrower than $6 \mathrm{~mm}$ in diameter (14). To address this problem, Stack et al. developed a biodegradable scaffold with poly-L-lactide $(\operatorname{PLLA})(15,16)$, wherein the biodegradable membrane decomposes into harmless molecules (17). Poly(L-lactide-co-caprolactone) $[\mathrm{P}(\mathrm{LLA}-\mathrm{CL})]$ is a biodegradable material that can combine drugs stably and shows excellent mechanical properties $(18,19)$. In addition, the biodegradation rate of $\mathrm{P}(\mathrm{LLA}-\mathrm{CL})$ can be controlled by adjusting the molar ratio of PLLA in the copolymer, which makes it more suitable as a stent coating material.

Although previous studies have found that stent-induced platelet and EC activations can increase the risk of stenosis (20), the anticoagulant heparin can reduce thrombosis and prolong blood clotting after endothelial injury. Because rosuvastatin can promote EC proliferation and inhibit and inflammatory-SMC proliferation (21), the combination of heparin and rosuvastatin may emerge as an effective drug coating for application to next-generation stents. Therefore, in this study, a nanofiber-covered stent was prepared by coaxial-electrospinning a stable, biodegradable copolymer and was loaded with both heparin and rosuvastatin.

\section{Results}

\subsection{Fabrication and structural characteristics of nanofiber mats and covered stent}

Using coaxial electrospinning, nanofiber mats were fabricated (Fig. 1Aa). Nanofiber mats wrapped the stent grafts completely to form covered stents (Fig. 1Ab). The magnified images clearly show that the nanofiber mats are composed of fibrous structures and do not show any structural dissolution at $37^{\circ} \mathrm{C}$ (Fig. 1AC). The morphology of the nanofiber scaffolds was observed under TEM. The shell is light and thin and shows clear edges, and the drug-loaded core is dark. Neither shows any aggregation or discontinuity (Fig. 1Ad).

Figure 1B shows that the mean diameters of the Rosu 50, Rosu 75, and Rosu 100 core-shell fibers were slightly thicker than that of the PBS fiber. However, there were no statistical differences between their diameters.

\subsection{Effects of heparin-rosuvastatin-loaded nanofiber scaffolds on synthetic SMCs}

SMCs are the key contributor to late in-stent stenosis, and SMC morphology is highly correlated with SMC phenotypic functions. Under SEM observation, the SMCs appeared as flat triangles and as lesscontracted spindles in the PBS group. With increasing rosuvastatin ratio, the cell morphology was spindle-like in the Rosu 50 and Rosu 75 groups, and the number of flat triangular cells decreased. In the Rosu 100 group, cells were slender spindle-like, and their morphological changes were more obvious than those of the cells in the PBS group (Fig. 2A). Phalloidin staining showed that with increasing rosuvastatin concentration, the cell morphology gradually became spindle-like (Fig. 2B). The Hoechst-33342 staining 
showed that with increasing rosuvastatin ratio, the number of attached synthetic SMCs decreased (Fig. 2C). Using CCK-8, we quantified the number of synthetic SMCs attached to the nanofiber scaffolds. After 24 and $48 \mathrm{~h}$ of culturing, the synthetic SMCs proliferated the most in the PBS group, and the proliferation activity decreased with increasing rosuvastatin ratio, showing a negative correlation (Fig. 2D). The inflammatory factors secreted by cells can be detected using the MILLIPLEX® Map kit. The inflammatory factors decreased significantly in the Rosu 100 group compared with the PBS one. (Fig. 3).

\subsection{Balloon-expansion assay}

After the attached-cell experiment, we preliminarily chose Rosu 100 as the most suitable volume ratio and fabricated nanofibers on stents for 3, 5, and 10 min to test different thicknesses. Figure 4 shows the results of the balloon-expansion experiment. For the nanofibers spun for $10 \mathrm{~min}$, the proximal and distal ends of the stent began to expand at 4 bar. However, the expanded balloon could not drive the middle segment to expand, leading to a dog-bone-like stent graft. At 6.5 bar, the stent opened in pulsations. At 9 bar, no translucent phenomenon could be observed. The covered nanofiber mats still retained a certain thickness and remained wrapped around the stent, thereby limiting stent expansion. Simultaneously, tiny cracks could be observed on the covered mats. At 9.5 bar, the balloon ruptured and leaked. For the nanofibers spun for $5 \mathrm{~min}$, the proximal and distal ends of the stent began to expand at 4 bar. When the filling pressure reached 6 bar, the stent expanded in pulsations and when the pressure reached 9.5 and 10 bar, although the nanofiber mats appeared transparent and still covered the stent, fine cracks could be seen. For the nanofibers spun for $3 \mathrm{~min}$, the proximal and distal ends of the stent began to expand at 3.5 bar, the dog-bone shape disappeared at 5 bar, and the stent expanded completely, which was different from the other two nanofiber mats. When the stent expanded completely, the mats clearly were wrapped around the stent, and the stent expanded smoothly without sudden expansion. When the filling pressure reached 6 bar, the stent was completely expanded, and the mat remained intact. The scatter chart prepared according to data obtained for the stent outer diameter shows that the outer diameter of the stent graft can be expanded with changing pressure. The optimal pad thickness was obtained for the nanofiber scaffolds spun for 3 min; therefore, we carried out the remaining experiments on those stents.

\subsection{Rabbit aneurysm model development, stent implantation, and short- and long-term follow-ups}

The rabbit aneurysms were induced by injecting porcine pancreatic elastase into the right common carotid arteries (CCAs) of New Zealand white rabbits (Fig. 5Aa). After induction, the right CCA was larger than a normal blood vessel, forming a longitudinal aneurysm body. The right subclavian artery was the parent artery (Fig. 5Ab). DSA was performed $30 \mathrm{~d}$ after aneurysm induction. Angiography showed that aneurysms were induced (Fig. 5Ac), and the covered stent was delivered to the parent artery to cover the aneurysm neck. With the expansion of the covered stent, the aneurysm body completely disappeared in the DSA images (Fig. 5Ad).

After stent implantation, aneurysms were divided into three grades and used to evaluate the therapeutic effect during follow-up. Table 1 shows the grading standards. Figure 5B shows the angiography images 
of the 3 grades. Most of the stents achieved good coverage on immediate postoperative angiography after stent implantation, and there was no significant difference between the PBS and Rosu 100 groups. However, at the 3-month (short-term) follow-up in the PBS group, the number of type A grade decreased by $40 \%$, while types $B$ and $C$ grade both increased by $50 \%$. Meanwhile, the number of each grade in the Rosu 100 group did not change, and the stent did not further promote thrombosis in the aneurysms. At the 12-month (long-term) follow-up, the number of type A grade in the PBS group decreased by $33 \%$, and the number of types $B$ and $C$ grade both increased by 1 . The Rosu 100 group showed one case of slight blood leakage into the aneurysm cavity after treatment, which had been rated as type $B$ grade after the operation. At the 12-month follow-up, the aneurysm with the original type B grade was no longer developed, and all three aneurysms were cured, reaching type A grade (Fig. 5B). We further analyzed the changes in the parent artery after stent implantation and found that in both the short- and long-term follow-ups, there was no obvious stenosis in the parent arteries (Fig. 5C).

Table 1

Aneurysm classification

\begin{tabular}{|c|c|}
\hline Type & Description \\
\hline $\begin{array}{l}\text { Type } \\
\text { A }\end{array}$ & $\begin{array}{l}\text { Aneurysm did not show any recanalization or bleeding after stent implantation and } f \\
\text { up }\end{array}$ \\
\hline $\begin{array}{l}\text { Type } \\
\text { B }\end{array}$ & $\begin{array}{l}\text { Dog-ear-shaped aneurysm showed mild blood leakage after stent implantation and fo } \\
\text { up }\end{array}$ \\
\hline $\begin{array}{l}\text { Type } \\
\text { C }\end{array}$ & $\begin{array}{l}\text { Aneurysm obviously had not healed and had recanalized after stent implantation and } \\
\text { follow-up }\end{array}$ \\
\hline
\end{tabular}

\subsection{Histology analysis}

SEM and H\&E staining showed better endothelial coverage in the Rosu 100 group (Figs. 6 Ac, $d, f$ ) than in the PBS one at the 3-month follow-up (Figs. 6Aa, b, e). In the long-term follow-up (Fig. 6B), the PBS and Rosu 100 groups both showed similar endothelial coverages.

In the toxicity experiment, no inflammatory reaction could be seen in H\&E staining at either 1 or 3 months. (Fig. 6C).

\subsection{PDGF-BB-induced synthetic SMC model and viability of rosuvastatin-treated SMCs}

Figure S1A demonstrates that $10 \mathrm{ng} / \mathrm{mL}$ PDGF-BB can significantly increase SMC viability in $24 \mathrm{~h}$ ( $p<$ 0.0001). Meanwhile, the proliferation activity of SMCs increased with increasing rosuvastatin concentration. However, at $1000 \mathrm{ng} / \mathrm{mL}$, the proliferation activity decreased, suggesting adverse reactions. Figure S1B shows the results for the rosuvastatin treatment of contractile SMCs. Clearly, although contractile-SMC proliferation was not significantly inhibited at lower rosuvastatin concentrations $(p>0.05)$, it was significantly inhibited at $100 \mu \mathrm{M}(p<0.0001)$. To determine the effective 
inhibitory rosuvastatin concentration for PDGF-BB, we treated SMCs with $10 \mathrm{ng} / \mathrm{mL}$ PDGF-BB and varied rosuvastatin concentration for $24 \mathrm{~h}$. The CCK-8 assay showed that $5 \mu \mathrm{M}$ rosuvastatin inhibited the PDGFBB-induced contractile-SMC proliferation $(p<0.05)$. The inhibitory effect was significant $(p<0.0001)$ at $10 \mu \mathrm{M}$ and strengthened with increasing rosuvastatin concentration (Figure S1C). Flow cytometry results showed that $10 \mu \mathrm{M}$ rosuvastatin calcium did not cause abnormal apoptosis in contractile SMCs (Figure S2). Therefore, we used $10 \mu \mathrm{M}$ rosuvastatin calcium for the subsequent experiments.

\subsection{SMC morphology, viability, and function}

Phalloidin staining revealed the cell morphology. In the PBS and Rosu groups, the cells remained spindleshaped, while the cells in the PDGF group appeared flatter and triangular. However, in the PDGF + Rosu group, because the ability of the PDGF-BB to change the SMC morphology was significantly inhibited, the cell morphology was more spindle-like (Fig. 7A).

EdU staining revealed that after stimulation with $10 \mathrm{ng} / \mathrm{mL}$ PDGF-BB for $24 \mathrm{~h}$, the number of SMCs labeled with EdU increased significantly (green, $p<0.0001$ ). When the cells were cotreated with rosuvastatin, the number of SMCs labeled with EdU decreased, which was significantly different from the trend for the PDGF group $(p<0.0001)$ (Fig. 7B).

In the scratch test, after $24 \mathrm{~h}$ of intervention, $67 \%$ of the remaining area in the control group remained unhealed while only $53 \%$ in the PDGF group did, which was significantly different from the control group $(p<0.001)$. Although the residual area in the PDGF + Rosu group was $66 \%$, which was significantly different from that in the PDGF group $(p<0.01)$, the residual area in the Rosu group was not notably different from that in the control group (Fig. 7C).

In the transwell assay, although the cell penetrabilities of the control and Rosu groups were weak compared with that of the control group, the number of cells that had penetrated the PDGF group increased significantly $(p<0.01)$. Although SMC migrability was substantially improved after PDGF-BB stimulation, the number of penetrating cells decreased after treatment with rosuvastatin, which was remarkably different from the trend in the PDGF group (Fig. 7D).

\subsection{Effects of rosuvastatin on SMC phenotype and inflammatory factors}

The PCR results showed that the expression of contractile phenotypic markers a-SMA and SM22-a was lower in the PDGF group than in the control group. After rosuvastatin treatment, the expression of a-SMA and SM22-a both increased; therefore, OPN was used for reverse verification. OPN was originally upregulated in the PDGF group and showed obvious attenuation after the rosuvastatin treatment. The expression of TNF-a, MCP-1, MMP-2, and MMP-9 also decreased substantially with the addition of rosuvastatin (Fig. 8A)

The protein expression levels of phenotype markers and inflammatory factors in PDGF-BB-induced SMCs were detected by western blotting. The results showed that SM22-a and OPN were notably downregulated 
and upregulated after PDGF-BB stimulation, respectively, and that the protein expression of MMP-9 was also notably increased after PDGF-BB stimulation. With the addition of rosuvastatin, the SM22-a and OPN expressions increased and decreased, respectively (Fig. 8B).

The inflammatory factors secreted by cells can be detected using the MILLIPLEX® Map. After PDGF-BB stimulation, the inflammatory factors increased, and the secretion of IL-1 $\beta$ was up to 4 times that of the control group. Compared with the PDGF group, the ability of the rosuvastatin-treated SMCs to secrete inflammatory factors decreased, and there was a significant difference compared with the PDGF-BB group (Fig. 8C).

\section{Discussion}

To prevent stent stenosis and thrombosis, drugs loaded on covered stent grafts should be able to regulate cell proliferation, inflammatory reactions, and thrombosis. After stent implantation, effective anticoagulation and inhibition of platelet adhesion are the first steps. Heparin plays a major role in anticoagulation therapy. Although the heparin coating reduced the thrombosis rate in animal experiments $(22,23)$, it could not effectively improve late vascular patency and neointimal hyperplasia (24), suggesting that promoting the proliferation ability of ECs is crucial. In our previous study, we found that rosuvastatin- and heparin-coated stents could effectively promote early endothelialization and provide a basis for reducing long-term complications(25). Early endothelialization is the key to preventing in-stent stenosis and late thrombosis $(26,27)$. Willis covered stents are widely used in the treatment of complex aneurysms. However, although ePTFE reduces the incidence of early stent-graft stenosis, it is also prone to delayed reendothelialization (28). Nondegradable polymers that remain in arteries can continue to cause local inflammatory reactions (29). In patients treated with PTFE-covered stents, the incidence of nonfatal myocardial infarction is higher than that in patients treated with a bare metal stent (30).

Although PLLA is a biodegradable synthetic polymer, it shows poor flexibility. Blending PLLA with a moreelastic polymer is an effective method of improving its mechanical properties $(31,32)$. Previous studies have shown that the $\mathrm{P}(\mathrm{LLA}-\mathrm{CL})$ nanofiber membrane shows good EC adhesion (33); therefore, we chose $\mathrm{P}(\mathrm{LLA}-\mathrm{CL})$ to lay the foundation for the development of the nanofiber scaffolds. Because the cover mats of the Willis stent graft are loosely sutured to the stent (34), the nanofibers may be damaged during placement (35). Studies have confirmed that nanofiber scaffolds prepared by coaxial electrospinning are less likely to be damaged, and coaxial electrospinning can not only load drugs evenly on polymers but also facilitate drug release. Furthermore, coaxial electrospinning can prepare shell-core structures (33, 36), allowing for polymer drug loading, which is beneficial to the combination of drugs and polymers. Uniform drug loading can provide a good foundation for drug release, and sustained drug release can provide a stable therapeutic effect. In addition, in cerebral arteries, the stent-graft must be miniaturized and show high flexibility and maneuverability to smoothly navigate to the target artery (37). Therefore, we used an Apollo stent made of $316 \mathrm{~L}$ stainless steel, which shows sufficient supporting force, and its special spatial structure can provide effective toughness when the stent expands, which is critical because excessive pressure during balloon expansion can lead to thromboembolism, vascular dissection, or rupture (38). The expansion pressure of a bare Apollo stent is only 6 bar. When the nanofiber was spun 
for $3 \mathrm{~min}$, the membrane did not break or fall off at 6 bar, indicating that a 3-min-thick membrane is more suitable so that the stent can be completely opened under lower pressures without affecting the pressure of the Apollo stent itself. Therefore, we adopted the balloon catheter expandable stent and set the membrane thickness at 3 min.

The elastase-induced rabbit aneurysm is a mature aneurysm model (39). Different animal models have different research objectives. In the cardiovascular system, the porcine coronary artery model can be used to evaluate the risk of stent stenosis. The tendency of thrombosis and neointimal formation in the porcine coronary system is similar to that in humans, which is especially helpful in evaluating arterial stenosis after stent implantation $(40,41)$. However, the porcine coronary artery is unsuitable for simulating the environment of small arteries. In addition to porcine and rodent models, the atherosclerosis model of New Zealand white rabbits can also be used to evaluate stent stenosis. Stents were implanted in New Zealand white rabbits fed a high-fat diet to evaluate in-stent stenosis. Compared with the porcine model, the in-stent stenosis model of New Zealand white rabbits is more suitable for observing the drug mechanism $(42,43)$. The use of a rabbit CCA model to evaluate in-stent stenosis is also an emerging method, and studies have found that it is not different from traditional methods (44).

The traditional flow-diverter device shows only $56 \%$ occlusion at the 3-month follow-up, and it takes 12 months to reach $95 \%$ occlusion (45). In our study, the aneurysm was immediately excluded from the blood flow after the covered stent was placed, and the aneurysm was no longer visible. In addition, studies have shown that if there is a mild endoleak after the covered stent has been implanted, leakage can eventually occluded (35). In our long-term follow-up, a type $C$ aneurysm sprang a leak, and the aneurysm was still visible after stent implantation. After treatment with the Rosu 100-covered stent for 12 months, the aneurysm was no longer visible. SEM observation showed that the endothelial coverage of the aneurysm neck was intact. However, in the PBS group that was originally satisfactory after the treatment, only one case did not leak or recanalize at the 12-month follow-up, suggesting that the heparin and rosuvastatin loads showed a certain therapeutic effect and a stable aneurysm cure rate.

After vascular injury, SMCs can transform from a resting contractile type to a pro-inflammatory, dedifferentiated one. The phenotypic regulation of VSMCs, which describes SMC differentiation, was first conceptualized by Chamley-Campbell et al. (46). When the differentiated type is modulated to the dedifferentiated one, inflammatory cytokines are produced and inflammatory cell markers are expressed $(47,48)$, involving the participation of multiple cytokines (49). PDGF-BB is one of the key factors affecting the phenotypic modulation of SMCs $(50,51)$, which promotes the SMC morphology to change from spindle-shaped to flat triangular or oblique squares (52). When PDGF-BB is inhibited, the concentration of contractile-type markers a-SMA and SM-22a begin to increase (53). Studies have found that rosuvastatin has pleiotropic effects and can reduce SMC phenotypic modulation (54). In our study, PDGF-BB was used to construct a model of inflammatory SMCs to simulate the cytokines released by endothelial injury and the affected SMC phenotype modulation. We found that PDGF-BB stimulated SMC proliferation and migration. Once the PDGF-BB concentration increased, the expression of OPN was substantially increased, and the expression of phenotypic marker molecules of contractile SMCs was reduced, 
suggesting that the cytokines released after endothelial damage could regulate the SMC phenotype. On the nanofiber mats, we observed that the increase in rosuvastatin concentration reduced the number of PDGF-BB-stimulated SMCs and gradually restored their shape to spindle-like. Our results confirmed that the rosuvastatin-loaded nanofiber functioned by inhibiting the abnormal proliferation of SMCs. Studies have found that statins can inhibit the transduction of PDGF-BB on SMCs by blocking the G0/G1 cell cycle and PDGFRß-Akt signaling cascade (55), thereby inhibiting the pathological proliferation and migration of SMCs (56). Simvastatin can reduce the secretion and mRNA expression of PDGF/IL-1induced MMP-9 and reduce MMP-9 secretion in vascular smooth-muscle cells by inhibiting the RhoA/ROCK signaling pathway (57), thereby reducing the transduction of the SMC inflammatory response. After we constructed a PDGF-BB cell model, rosuvastatin was used to treat SMCs, and we found that rosuvastatin could inhibit PDGF-BB to promote the proliferation and migration of inflammatory SMCs. Analysis of the secreted supernatant revealed that the expression of inflammatory factors in rosuvastatin-treated SMCs decreased, which confirmed that rosuvastatin calcium can effectively regulate the phenotype of smooth-muscle cells.

\section{Conclusions}

This study explored the application of a nanofiber-covered stent in vivo and its mechanism in vitro. In vitro experiments demonstrated that rosuvastatin can inhibit the proliferation and migration of inflammatory SMCs and inhibit the PDGF-BB-induction of SMCs. In-vivo studies revealed that the covered stent did not cause persistent inflammatory reactions in tissues. The therapeutic effect of the Rosu 100covered stent was ideal for treating rabbit RCCA aneurysms. The results suggest that drug-loaded covered stents may reduce the risk of late in-stent thrombosis and stenosis.

\section{Materials And Methods}

\subsection{Nanofiber-covered stent fabrication}

$\mathrm{P}(\mathrm{LLA}-\mathrm{CL})$ was dissolved in $10 \mathrm{~mL}$ of hexafluoroisopropanol to prepare a $120 \mathrm{mg} / \mathrm{mL}$ shell solution. The core solution was prepared with $15 \%$ heparin and $20 \mu \mathrm{M}$ rosuvastatin (Sigma-Aldrich, Merck, German) solution. The volumetric ratios of heparin to rosuvastatin were 450:50 (450:50 $(\mu \mathrm{L})), 425: 75(425: 75$ $(\mu \mathrm{L}))$, and 400:100 (400:100 $(\mu \mathrm{L}))$. The control group used phosphate-buffered saline (PBS) solution to replace heparin and rosuvastatin. The nanofiber mats were named PBS, Rosu 50, Rosu 75, and Rosu 100 according to the different rosuvastatin volumetric ratios. An Apollo bare metal stent made of $316 \mathrm{~L}$ stainless steel (MicroPort Co., Ltd., China) was placed 10-25 cm away from the tip of the syringe pump (KDS 200, KD Scientific, Holliston, MA). The core and shell solutions were used to fabricate coaxial nanofiber-covered stents. The structure of covered stent was observed under a transmission electron microscope (TEM; Hitachi, Japan)

\subsection{Nanofiber diameter measurement}


Four groups of sterilized nanofiber scaffolds were soaked in Dulbecco's Modified Eagle Medium (DMEM, Hyclone,Utah) for $24 \mathrm{~h}$ in triplicate and were observed using scanning electron microscopy (SEM; Phenom $\mathrm{XL}$, the Netherlands). The diameters of 100 fibers, as shown in the SEM images, were measured and recorded.

\subsection{Characterization of nanofiber scaffolds}

PBS, Rosu 50, Rosu 75, and Rosu 100 were fumigated with 75\% alcohol for $3 \mathrm{~d}$ and then sterilized by ultraviolet radiation for 30 min to prepare sterile scaffold mats. SMCs were stimulated with $10 \mathrm{ng} / \mathrm{mL}$ platelet-derived growth factor-BB (PDGF-BB; PeproTech, USA) for $24 \mathrm{~h}$ before seeding. SMCs were seeded into four groups of nanofiber mats at a density of $2 \times 10^{4}$ cells/well in triplicate. After 24 and $48 \mathrm{~h}$, the intervention was terminated, glutaraldehyde was added to fix the cells, and the samples were observed by SEM. Three regions of each sample were selected for observation.

\subsection{Hoechst staining of cells attached to nanofiber mats}

SMCs were stimulated with $10 \mathrm{ng} / \mathrm{mL}$ PDGF-BB for $24 \mathrm{~h}$ and were seeded on nanofiber mats at a density of $2 \times 10^{4}$ cells/well in triplicate and then cultured for $48 \mathrm{~h}$. After fixing the cells with $4 \%$ paraformaldehyde (PFA; Sinopharm, China) overnight, nanofiber mats were stained with Hoechst 33342 (Beyotime, China) for $5 \mathrm{~min}$, following the manufacturer's instructions. Samples were photographed using a confocal fluorescence microscope (Carl Zeiss, Germany). The Hoechst-33342-labeled nuclei were stained blue.

\subsection{Analysis of attached-SMC viability}

SMCs were pretreated with $10 \mathrm{ng} / \mathrm{mL}$ PDGF-BB for $24 \mathrm{~h}$ and seeded into 4 groups of nanofiber mats at a density of $10^{4}$ /well in triplicate. A cell counting Kit-8 assay (CCK-8; Dojindo, Japan) was conducted according to the manufacturer's instructions to study the viability of the cells on the scaffold mats. The seeded mats were cultured for either 24 or 48 h, $500 \mu \mathrm{L}$ of CCK-8 staining solution was then added to each well, and the mats were incubated for 2-3 h. The absorbance at $450 \mathrm{~nm}$ was measured with a microspectrophotometer (ThermoFisher Scientific ${ }^{\mathrm{TM}}$, Waltham, Massachusetts).

\subsection{Balloon-expansion experiment}

The covered stent was connected to a balloon catheter (MicroPort Co., Ltd. Shanghai, China) and was gradually filled with $0-10$ bar $(0-1000 \mathrm{kPa})$ of air for expansion. The outer diameters of the proximal, distal, and middle segments of the covered stent were measured and statistically graphed using GraphPad Prism 8.0 software.

\subsection{Development of rabbit aneurysm model and stent implantation}

The New Zealand white rabbit common-carotid-aneurysm model has been explained in detail in our previous paper (58). Thirty (30) $d$ after modeling, which was sufficient for the aneurysm to mature, digital subtraction angiography (DSA) was used to observe the aneurysm formation. Covered stents were placed 
into the right subclavian artery and were maintained at equal lengths on either side of the aneurysm ostium. According to the results of the in vitro assay, Rosu 100 and PBS were used in the experiment and control groups, respectively. The stents were randomly selected from the PBS and Rosu 100 groups. Immediately after the procedure, DSA was used to evaluate blood flow in the aneurysm. Based on the DSA characteristics, therapeutic efficacy was divided into 3 grades, as shown in Table 1.

\subsection{Rabbit aneurysm short- and long-term follow-ups}

The treated animals were administered aspirin $(20 \mathrm{mg} / \mathrm{d}) 7 \mathrm{~d}$ prior to and $14 \mathrm{~d}$ after stenting. Therapeutic efficacy was evaluated with DSA at 3 and 12 months after stenting and was divided into 3 grades. Stent grafts were collected at 3 and 12 months after stent implantation, and SEM and histology were used to observe the endothelialization of the parent artery.

\subsection{Histology}

Specimens were fixed with 4\% PFA overnight and dehydrated with gradient alcohol $(75,85,90,95$, and $100 \%$ ) for $24 \mathrm{~h}$. Then, the specimens were soaked in xylene for $4 \mathrm{~h}$ and treated with curing monomers I, II, and III for $24 \mathrm{~h}$, after which the specimens were encased in monomers $1-1.5 \mathrm{~cm}$ above the tops of the tissue specimens themselves by adding the curing monomer and using a gas pump in a dryer to prevent bubble formation. The tissue specimens were deposited at $4^{\circ} \mathrm{C}$ for one week, further deposited at room temperature until the monomer thickened, and then transferred into an oven $\left(37^{\circ} \mathrm{C}\right)$ until the monomer hardened. After the methyl methacrylate (MMA) was completely hardened, a LeicaSP600 hard tissue slicer (Leica) was used to prepare 100- $\mu$ m-thick tissue sections, which were further polished to $50 \mu \mathrm{m}$, sealed, and repolished. We observed the sections and calculated the coverage ratio for all the stents in each section. A t-test was used for statistical analysis.

\subsection{Toxicity of nanofiber mats}

The nanofiber mats were implanted under the abdominal skin of C57 male mice. Tissue specimens were collected 1 and 3 months after implantation and were stained with hematoxylin and eosin (H\&E) to observe the inflammatory reaction of the mats on the tissue.

\subsection{Viabilities of PDGF-BB-induced inflammatory, rosuvastatin-treated, and rosuvastatin-treated inflammatory SMCs}

PDGF-BB was used to establish an inflammatory-SMC model. PDGF-BB was dissolved in sterilized $\mathrm{H}_{2} \mathrm{O}$ and diluted with DMEM to $0,1,10,20,50,100$, and $1000 \mathrm{ng} / \mathrm{mL}$. Rat aortic SMCs were seeded onto 96well plates at a density of $3 \times 10^{3}$ cells/well in triplicate and cultured in DMEM supplemented with $10 \%$ fetal bovine serum (FBS; Epizyme, China). When the cells reached $50-60 \%$ confluence, SMCs were incubated in the serum-starvation condition for $24 \mathrm{~h}$. Cell viability was measured using the CCK-8 assay. The absorbance was measured at $450 \mathrm{~nm}$ using a spectrometer. 
The toxicity of rosuvastatin on contractile SMCs was further evaluated. Similarly, cells were seeded into 96-well plates at $3 \times 10^{3} /$ well in triplicate and further subjected to starvation conditions for $24 \mathrm{~h}$.

Rosuvastatin was dissolved in dimethyl sulfoxide (DMSO; Simga-aldrich, Merck, Germany) and diluted with DMEM to $0,0.01,0.1,1,10,20$, and $100 \mu \mathrm{M}$. Cell viability was measured with the CCK-8 assay, as previously described in this section.

The effective rosuvastatin concentration that inhibited PDGF-BB was further explored. Cells were seeded and starved under the same conditions previously described in this section. After $24 \mathrm{~h}$, cells were treated with a mixed solution of $10 \mathrm{ng} / \mathrm{mL}$ PDGF-BB and different doses of rosuvastatin $(0,0.01,0.1,1,5,10,20$, and $100 \mu \mathrm{M}$ for 24 or $48 \mathrm{~h}$. Cell viability was again measured using the CCK-8 assay kit.

\subsection{Phalloidin assay}

SMCs were stimulated with $10 \mathrm{ng} / \mathrm{mL}$ PDGF-BB for $24 \mathrm{~h}$, seeded on nanofiber mats at a density of $2 \times$ $10^{4} /$ well, and cultured for $48 \mathrm{~h}$. The cultured cells were fixed with $4 \%$ PFA overnight and stained with phalloidin solution for 60 min according to the manufacturer's instructions. The cells were counterstained with 4',6-diamidino-2-phenylindole (DAPl; Bioss, China) for $10 \mathrm{~min}$. Similarly, the SMCs were seeded into 24-well plates at a density of $1.5 \times 10^{4} /$ well and were cultured for $24 \mathrm{~h}$. The cultured SMCs were then starved for $24 \mathrm{~h}$. The cells were fixed and stained with phalloidin solution (Meilunbio, China) and DAPI, as previously described in this section. A confocal fluorescence microscope was used to observe the cytoskeleton.

\subsection{Cell proliferation assay}

SMCs were seeded into 24 -well plates at a density of $2 \times 10^{4} /$ well in triplicate. The cells were starved prior to the intervention and were divided into groups as follows: the control and SMCs stimulated with 10 $\mathrm{ng} / \mathrm{mL}$ PDGF-BB (PDGF), treated with $10 \mu \mathrm{M}$ Rosuvastatin (Rosu), and cotreated with $10 \mathrm{ng} / \mathrm{mL}$ PDGF-BB and $10 \mu \mathrm{M}$ rosuvastatin (PDGF + Rosu). Each group was cultured for $24 \mathrm{~h}$, after which an EdU cell proliferation detection kit (Beyotime, China) was used to evaluate the proliferation rate, according to the manufacturer's instructions. The cells were counterstained with Hoechst 33342 (Beyotime, China) for 10 min and then observed with a focused fluorescence microscope. Hoechst 33342 and EdU showed blue and green fluorescences, respectively. ImageJ software used to count the Hoechst-33342- and EdUlabeled cells, and the EdU/Hoechst-33342 ratio was then calculated.

\subsection{Scratch test}

Rat aortic SMCs were seeded into six-well plates at a density of $1 \times 10^{5} /$ well in triplicate. When reaching $80 \%$ density, the cells were cultured in serum-free DMEM for $24 \mathrm{~h}$. Pipette tips were used to scratch the cell monolayer across the center of each well. The detached cells were washed away with sterile PBS. 
The cells were divided into control, PDGF, Rosu, and PDGF + Rosu groups. Each group was cultured for 24 h. Three images were photographed for each well and were processed with ImageJ software. The areas in the images where cells remained after $24 \mathrm{~h}$ were compared.

\subsection{Transwell tests}

SMCs were seeded into a 12-well plate at a density of $5 \times 10^{4} /$ well in triplicate. The cells were starved prior to the intervention. The cells were then digested and seeded into 8- $\mu \mathrm{m}$-pore transwell chambers (Corning, NY) at a density of $1 \times 10^{4} /$ well. Then, $600 \mu \mathrm{L}$ of DMEM containing $10 \%$ FBS was added to the lower chamber in which the cells were incubated at $37^{\circ} \mathrm{C}$ for $6 \mathrm{~h}$. The upper chambers were replaced with serum-free DMEM and incubated for another $18 \mathrm{~h}$. The cells were then fixed with $4 \%$ PFA for 30 min at room temperature and then with crystal violet (Beyotime, China) for $5 \mathrm{~min}$. The cells attached to the interior of the upper chamber were removed with a cotton swab, and the chambers were placed on a new 24-well plate and were air-dried for $15 \mathrm{~min}$. The number of cells on the surface of the lower chamber were both calculated and photographed under a microscope.

\subsection{Cell apoptosis of rosuvastatin-treated contractile SMCs}

An Annexin V-FITC cell apoptosis detection kit (Beyotime, China) was used to detect the effect of rosuvastatin on contractile SMCs, according to the manufacturer's instructions. Flow cytometry (BD, New Jersey, USA) was used to detect Annexin V-FITC and propidium iodide (PI) showing green and red fluorescences, respectively.

\subsection{RNA extraction and real-time polymerase chain reaction}

The cellular ribonucleic acid (RNA) was isolated using an RNA purification kit (Yishan, China) according to the manufacturer's instructions. The RNA integrity was quantified using a NanoDrop ${ }^{\mathrm{TM}} 1000$ spectrophotometer (ThermoFisher Scientific ${ }^{\mathrm{TM}}$, UT, USA). The reverse transcription (RT) reaction was performed using a fast all-in-one RT kit (Yishan, China) according to the manufacturer's instructions. Real-time polymerase chain reaction (PCR) was performed using the Hieff® qPCR SYBR $®$ Green master mix (Yeasen, China) and was detected with a real-time PCR system $(7900 \mathrm{HT}, \mathrm{ABI})$. No nonspecific amplification was observed based on the dissociation curve. Glyceraldehyde 3-phosphate dehydrogenase (GAPDH; Sangon biotech, China) was used as an internal control. The data were further analyzed by the comparison $\mathrm{Ct}\left(2^{-\triangle \Delta C T}\right)$ method and were expressed as a fold change relative to the respective control. The sequences used for the APCR primers are listed in Table S1. 


\subsection{Western blot}

Proteins were lysed from the rat aortic SMCs after the intervention. The cells were divided into 4 groups, as described in above experiments, and $40 \mu \mathrm{g}$ of protein per lane was separated using $10 \%$ sodium dodecyl sulfate-polyacrylamide gel electrophoresis (SDS-PAGE; Epizyme, China). The proteins were electrotransferred onto a polyvinylidene difluoride (PVDF; Millipore Sigma, Billerica, MA, USA) membrane and blocked with a western quick-blocking buffer (Beyotime, China) for $15 \mathrm{~min}$ at room temperature. The blocked PVDF membranes were incubated overnight with primary antibodies including goat anti-SM22a (1:500 dilution; Abcam, England), rabbit anti-OPN (1:1000 dilution; Abcam, England), and rabbit antiMMP9 (1:1000 dilution; Abcam, England). After 12-14 h, the PVDF membranes were incubated with a horseradish-peroxidase-conjugated secondary antibody(Huabio, Chia) for $1 \mathrm{~h}$ at room temperature. The immunoblots were probed using an enhanced chemiluminescence (ECL; Thermo, Rockford, IL, USA) substrate. An imaging system (Bio-Rad, Hercules, CA, USA) was used to detect the blots, and the chemiluminescence levels were recorded. The results were normalized to that of GAPDH, and the experiments were replicated three times.

\subsection{Cytokine and chemokine analyses}

SMCs were seeded into a 24-well plate containing PBS, Rosu 50, Rosu 75, and Rosu 100 nanofiber mats at a density of $1 \times 104 /$ well. The cells were cultured for $48 \mathrm{~h}$, and the cellular supernatants were collected and used for interleukin-1 $\beta$ (IL-1 $\beta$ ), interleukin-6 (IL-6), monocyte chemoattractant protein-1 (MCP-1), tumor necrosis factor-a (TNF-a), vascular endothelial growth factor (VEGF), fractalkine (CX3CL1), and RANTES (CCL5) testing with a MILLIPLEX® MAP Rat cytokine/ chemokine factor panel (Millipore, Billerica, MA). Similarly, SMCs were transferred into a 24-well plate at a density of 2×104 cells/well, and the cells were treated as previously described in this section. DMEM was used as a control. At $24 \mathrm{~h}$, the culture supernatants were collected and tested for IL-1 $\beta$, IL-6, MCP-1, and TNF- $\alpha$ using a MILLIPLEX $\circledast$ MAP Rat CVD Panel (Millipore, Billerica, MA).

\section{Abbreviations}

P(LLA-CL), Poly(L-lactide-co-caprolactone); PDGF-BB, platelet-derived growth factor-BB; IA,intracranial aneurysm; DES, drug-eluting stents; SMCs, smooth-muscle cells; EC,endothelial-cell; PTFE, polytetrafluoroethylene; $\mathrm{PET}$, polyethylene terephthalate; TEM, transmission electron microscope; SEM,scanning electron microscopy; CCK-8, cell counting Kit-8 assay; H\&E, hematoxylin and eosin; FBS, fetal bovine serum; DMSO, dimethyl sulfoxide; DAPI, 4',6-diamidino-2-phenylindole; IL-1 $\beta$, interleukin-1 $\beta$; IL-6, interleukin-6; MCP-1, monocyte chemoattractant protein-1; TNF-a, tumor necrosis factor-a; VEGF, vascular endothelial growth factor; CX3CL1, fractalkine; CCL5, RANTES; CCA, common carotid arteries; DSA,digital subtraction angiography

\section{Declarations}




\section{Ethic approval}

The study was examined and approved by the Ethics Committee of Huashan Hospital, Fudan University. (2017-263). Animal experiment protocols were approved by the Department of Laboratory Animal Science of Fudan University, Shanghai, China (201802041S).

\section{Availability of data and materials}

The datasets used and/or analysed during the current study are available from the corresponding author on reasonable request.

\section{Competing interests}

The authors declare that they have no competing interests.

\section{Funding}

This study was supported by The Outstanding Academic Leaders Program of Shanghai Municipal Commission of Health and Family Planning (No. 2017BR006 to WZ); National Natural Science Foundation of China (No. 81571102, No. 81870911 to WZ; No. 81801148 to PL); Clinical Research Plan of SHDC (No. SHDC2020CR2034B to WZ, No. SHDC2020CR4033 to KQ); Shanghai Municipal Science and Technology Major Project (No.2018SHZDZX01) and ZJ Lab; CAMS Innovation Fund for Medical Sciences (CIFMS, 2019-I2M-5-008).

\section{Authors' contributions}

YJL wrote the main manuscript. YJL and PXL established the rabbit aneurysm models. YJL and YYS carried out the in vitro experiment. PLL, QZA and GY performed DSA surgery. SCL and YS helped analyzed the data, and partial in vitro experiment. WZ supervised the project and were in charge of overall direction. All authors read and approved the final manuscript.

\section{References}

1. Etminan N, Rinkel GJ. Unruptured intracranial aneurysms: development, rupture and preventive management. Nat Rev Neurol. 2016;12(12):699-713.

2. Greving JP, Wermer MJ, Brown RD, Jr., Morita A, Juvela S, Yonekura M, et al. Development of the PHASES score for prediction of risk of rupture of intracranial aneurysms: a pooled analysis of six prospective cohort studies. Lancet Neurol. 2014;13(1):59-66. 
3. Nieuwkamp DJ, Setz LE, Algra A, Linn FH, de Rooij NK, Rinkel GJ. Changes in case fatality of aneurysmal subarachnoid haemorrhage over time, according to age, sex, and region: a metaanalysis. Lancet Neurol. 2009;8(7):635-42.

4. Molyneux A, Kerr R, Stratton I, Sandercock P, Clarke M, Shrimpton J, et al. International Subarachnoid Aneurysm Trial (ISAT) of neurosurgical clipping versus endovascular coiling in 2143 patients with ruptured intracranial aneurysms: a randomised trial. Lancet. 2002;360(9342):1267-74.

5. Molyneux AJ, Kerr RS, Yu LM, Clarke M, Sneade M, Yarnold JA, et al. International subarachnoid aneurysm trial (ISAT) of neurosurgical clipping versus endovascular coiling in 2143 patients with ruptured intracranial aneurysms: a randomised comparison of effects on survival, dependency, seizures, rebleeding, subgroups, and aneurysm occlusion. Lancet. 2005;366(9488):809-17.

6. Wiebers DO, Whisnant JP, Huston J, 3rd, Meissner I, Brown RD, Jr., Piepgras DG, et al. Unruptured intracranial aneurysms: natural history, clinical outcome, and risks of surgical and endovascular treatment. Lancet. 2003;362(9378):103-10.

7. International Study of Unruptured Intracranial Aneurysms I. Unruptured intracranial aneurysms-risk of rupture and risks of surgical intervention. N Engl J Med. 1998;339(24):1725-33.

8. Marshman LA, Aspoas AR, Rai MS, Chawda SJ. The implications of ISAT and ISUIA for the management of cerebral aneurysms during pregnancy. Neurosurg Rev. 2007;30(3):177-80; discussion 80.

9. Guglielmi G, Vinuela F, Duckwiler G, Dion J, Lylyk P, Berenstein A, et al. Endovascular treatment of posterior circulation aneurysms by electrothrombosis using electrically detachable coils. $J$ Neurosurg. 1992;77(4):515-24.

10. Zhou Y, Yang PF, Fang YB, Xu Y, Hong B, Zhao WY, et al. A novel flow-diverting device (Tubridge) for the treatment of 28 large or giant intracranial aneurysms: a single-center experience. AJNR Am J Neuroradiol. 2014;35(12):2326-33.

11. Wang JB, Li MH, Fang C, Wang W, Cheng YS, Zhang PL, et al. Endovascular treatment of giant intracranial aneurysms with willis covered stents: technical case report. Neurosurgery. 2008;62(5):E1176-7; discussion E7.

12. Li MH, Li YD, Gao BL, Fang C, Luo QY, Cheng YS, et al. A new covered stent designed for intracranial vasculature: application in the management of pseudoaneurysms of the cranial internal carotid artery. AJNR Am J Neuroradiol. 2007;28(8):1579-85.

13. Lipinski MJ, Escarcega RO, Lhermusier T, Waksman R. The effects of novel, bioresorbable scaffolds on coronary vascular pathophysiology. J Cardiovasc Transl Res. 2014;7(4):413-25.

14. Zilla P, Bezuidenhout D, Human P. Prosthetic vascular grafts: wrong models, wrong questions and no healing. Biomaterials. 2007;28(34):5009-27.

15. Hara H, Nakamura M, Palmaz JC, Schwartz RS. Role of stent design and coatings on restenosis and thrombosis. Adv Drug Deliv Rev. 2006;58(3):377-86.

16. Stack RS, Califf RM, Phillips HR, Pryor DB, Quigley PJ, Bauman RP, et al. Interventional cardiac catheterization at Duke Medical Center. Am J Cardiol. 1988;62(10 Pt 2):3F-24F. 
17. Im SH, Jung Y, Kim SH. Current status and future direction of biodegradable metallic and polymeric vascular scaffolds for next-generation stents. Acta Biomater. 2017;60:3-22.

18. Shalumon KT, Sowmya S, Sathish D, Chennazhi KP, Nair SV, Jayakumar R. Effect of incorporation of nanoscale bioactive glass and hydroxyapatite in $\mathrm{PCL} /$ chitosan nanofibers for bone and periodontal tissue engineering. J Biomed Nanotechnol. 2013;9(3):430-40.

19. Li X, Su Y, He C, Wang H, Fong H, Mo X. Sorbitan monooleate and poly(L-lactide-co-epsiloncaprolactone) electrospun nanofibers for endothelial cell interactions. J Biomed Mater Res A. 2009;91(3):878-85.

20. Szuk T, Fejes Z, Debreceni IB, Kerenyi A, Edes I, Kappelmayer J, et al. Integrity((R)) bare-metal coronary stent-induced platelet and endothelial cell activation results in a higher risk of restenosis compared to Xience $((\mathrm{R}))$ everolimus-eluting stents in stable angina patients. Platelets. 2016;27(5):410-9.

21. Corsini A, Bellosta S, Baetta R, Fumagalli R, Paoletti R, Bernini F. New insights into the pharmacodynamic and pharmacokinetic properties of statins. Pharmacol Ther. 1999;84(3):413-28.

22. Haude M, Konorza TF, Kalnins U, Erglis A, Saunamaki K, Glogar HD, et al. Heparin-coated stent placement for the treatment of stenoses in small coronary arteries of symptomatic patients. Circulation. 2003;107(9):1265-70.

23. Kocsis JF, Llanos G, Holmer E. Heparin-coated stents. J Long Term Eff Med Implants. 2000;10(12):19-45.

24. De Scheerder I, Wang K, Wilczek K, Meuleman D, Van Amsterdam R, Vogel G, et al. Experimental study of thrombogenicity and foreign body reaction induced by heparin-coated coronary stents. Circulation. 1997;95(6):1549-53.

25. Liu P, Liu Y, Li P, Zhou Y, Song Y, Shi Y, et al. Rosuvastatin- and Heparin-Loaded Poly(I-lactide- cocaprolactone) Nanofiber Aneurysm Stent Promotes Endothelialization via Vascular Endothelial Growth Factor Type A Modulation. ACS Appl Mater Interfaces. 2018;10(48):41012-8.

26. Padfield GJ, Newby DE, Mills NL. Understanding the role of endothelial progenitor cells in percutaneous coronary intervention. J Am Coll Cardiol. 2010;55(15):1553-65.

27. Kipshidze N, Dangas G, Tsapenko M, Moses J, Leon MB, Kutryk M, et al. Role of the endothelium in modulating neointimal formation: vasculoprotective approaches to attenuate restenosis after percutaneous coronary interventions. J Am Coll Cardiol. 2004;44(4):733-9.

28. Dangas GD, Claessen BE, Caixeta A, Sanidas EA, Mintz GS, Mehran R. In-stent restenosis in the drugeluting stent era. J Am Coll Cardiol. 2010;56(23):1897-907.

29. O'Brien B, Zafar H, Ibrahim A, Zafar J, Sharif F. Coronary Stent Materials and Coatings: A Technology and Performance Update. Ann Biomed Eng. 2016;44(2):523-35.

30. Stankovic G, Colombo A, Presbitero P, van den Branden F, Inglese L, Cernigliaro C, et al. Randomized evaluation of polytetrafluoroethylene-covered stent in saphenous vein grafts: the Randomized Evaluation of polytetrafluoroethylene COVERed stent in Saphenous vein grafts (RECOVERS) Trial. Circulation. 2003;108(1):37-42. 
31. Wang W, Hu J, He C, Nie W, Feng W, Qiu K, et al. Heparinized PLLA/PLCL nanofibrous scaffold for potential engineering of small-diameter blood vessel: tunable elasticity and anticoagulation property. J Biomed Mater Res A. 2015;103(5):1784-97.

32. Broz ME, VanderHart DL, Washburn NR. Structure and mechanical properties of poly(D,L-lactic acid)/poly(epsilon -caprolactone) blends. Biomaterials. 2003;24(23):4181-90.

33. He W, Ma Z, Teo WE, Dong YX, Robless PA, Lim TC, et al. Tubular nanofiber scaffolds for tissue engineered small-diameter vascular grafts. J Biomed Mater Res A. 2009;90(1):205-16.

34. Zhu YQ, Li MH, Lin F, Song DL, Tan HQ, Gu BX, et al. Frequency and predictors of endoleaks and longterm patency after covered stent placement for the treatment of intracranial aneurysms: a prospective, non-randomised multicentre experience. Eur Radiol. 2013;23(1):287-97.

35. Ma L, Xu JC, Yan S, Feng H, Han HJ, Tan HQ, et al. A single-center experience in the endovascular treatment of carotid siphon aneurysms using the Willis covered stent: a retrospective analysis. J Neurointerv Surg. 2018;10(12):1197-202.

36. He C, Xu X, Zhang F, Cao L, Feng W, Wang H, et al. Fabrication of fibrinogen/P(LLA-CL) hybrid nanofibrous scaffold for potential soft tissue engineering applications. J Biomed Mater Res A. 2011;97(3):339-47.

37. Gu L, Santra S, Mericle RA, Kumar AV. Finite element analysis of covered microstents. J Biomech. 2005;38(6):1221-7.

38. Gross BA, Frerichs KU. Stent usage in the treatment of intracranial aneurysms: past, present and future. J Neurol Neurosurg Psychiatry. 2013;84(3):244-53.

39. Hoh BL, Rabinov JD, Pryor JC, Ogilvy CS. A modified technique for using elastase to create saccular aneurysms in animals that histologically and hemodynamically resemble aneurysms in human. Acta Neurochir (Wien). 2004;146(7):705-11.

40. Kantor B, Ashai K, Holmes DR, Jr., Schwartz RS. The experimental animal models for assessing treatment of restenosis. Cardiovasc Radiat Med. 1999;1(1):48-54.

41. Estevez-Loureiro R, Perez de Prado A, Perez-Martinez C, Cuellas-Ramon C, Regueiro-Purrinos M, Gonzalo-Orden JM, et al. Safety and Efficacy of New Sirolimus-eluting Stent Models in a Preclinical Study. Rev Esp Cardiol (Engl Ed). 2015;68(12):1118-24.

42. Joner M, Morimoto K, Kasukawa H, Steigerwald K, Merl S, Nakazawa G, et al. Site-specific targeting of nanoparticle prednisolone reduces in-stent restenosis in a rabbit model of established atheroma. Arterioscler Thromb Vasc Biol. 2008;28(11):1960-6.

43. Brasselet C, Durand E, Addad F, Vitry F, Chatellier G, Demerens C, et al. Effect of local heating on restenosis and in-stent neointimal hyperplasia in the atherosclerotic rabbit model: a dose-ranging study. Eur Heart J. 2008;29(3):402-12.

44. Wang G, Luo X, Zhang R, Chen S, Hou J, Yu B. A Novel Rabbit Model for In-Stent Neoatherosclerosis. Int Heart J. 2019;60(5):1154-60.

45. Lylyk P, Miranda C, Ceratto R, Ferrario A, Scrivano E, Luna HR, et al. Curative endovascular reconstruction of cerebral aneurysms with the pipeline embolization device: the Buenos Aires 
experience. Neurosurgery. 2009;64(4):632-42; discussion 42-3; quiz N6.

46. Chamley-Campbell J, Campbell GR, Ross R. The smooth muscle cell in culture. Physiol Rev. 1979;59(1):1-61.

47. Nakayama K, Shimojo S. Experiencing and perceiving visual surfaces. Science. 1992;257(5075):1357-63.

48. Hansson GK, Jonasson L, Holm J, Claesson-Welsh L. Class II MHC antigen expression in the atherosclerotic plaque: smooth muscle cells express HLA-DR, HLA-DQ and the invariant gamma chain. Clin Exp Immunol. 1986;64(2):261-8.

49. Rong JX, Berman JW, Taubman MB, Fisher EA. Lysophosphatidylcholine stimulates monocyte chemoattractant protein-1 gene expression in rat aortic smooth muscle cells. Arterioscler Thromb Vasc Biol. 2002;22(10):1617-23.

50. Kim JY, Kim KH, Lee WR, An HJ, Lee SJ, Han SM, et al. Apamin inhibits PDGF-BB-induced vascular smooth muscle cell proliferation and migration through suppressions of activated Akt and Erk signaling pathway. Vascul Pharmacol. 2015;70:8-14.

51. Miyazawa K, Kikuchi S, Fukuyama J, Hamano S, Ujiie A. Inhibition of PDGF- and TGF-beta 1-induced collagen synthesis, migration and proliferation by tranilast in vascular smooth muscle cells from spontaneously hypertensive rats. Atherosclerosis. 1995;118(2):213-21.

52. Hao H, Ropraz P, Verin V, Camenzind E, Geinoz A, Pepper MS, et al. Heterogeneity of smooth muscle cell populations cultured from pig coronary artery. Arterioscler Thromb Vasc Biol. 2002;22(7):1093-9.

53. Dong X, Hu H, Fang Z, Cui J, Liu F. CTRP6 inhibits PDGF-BB-induced vascular smooth muscle cell proliferation and migration. Biomed Pharmacother. 2018;103:844-50.

54. Stancu C, Sima A. Statins: mechanism of action and effects. J Cell Mol Med. 2001;5(4):378-87.

55. Llorente-Cortes V, Martinez-Gonzalez J, Badimon L. Differential cholesteryl ester accumulation in two human vascular smooth muscle cell subpopulations exposed to aggregated LDL: effect of PDGFstimulation and HMG-CoA reductase inhibition. Atherosclerosis. 1999;144(2):335-42.

56. Chen S, Dong S, Li Z, Guo X, Zhang N, Yu B, et al. Atorvastatin Calcium Inhibits PDGF-betabetaInduced Proliferation and Migration of VSMCs Through the G0/G1 Cell Cycle Arrest and Suppression of Activated PDGFRbeta-PI3K-Akt Signaling Cascade. Cell Physiol Biochem. 2017;44(1):215-28.

57. Turner NA, O'Regan DJ, Ball SG, Porter KE. Simvastatin inhibits MMP-9 secretion from human saphenous vein smooth muscle cells by inhibiting the RhoA/ROCK pathway and reducing MMP-9 mRNA levels. FASEB J. 2005;19(7):804-6.

58. Liu Y, Zheng Y, An Q, Song Y, Leng B. Optical Coherence Tomography for Intracranial Aneurysms: A New Method for Assessing the Aneurysm Structure. World Neurosurg. 2019;123:e194-e201.

\section{Figures}




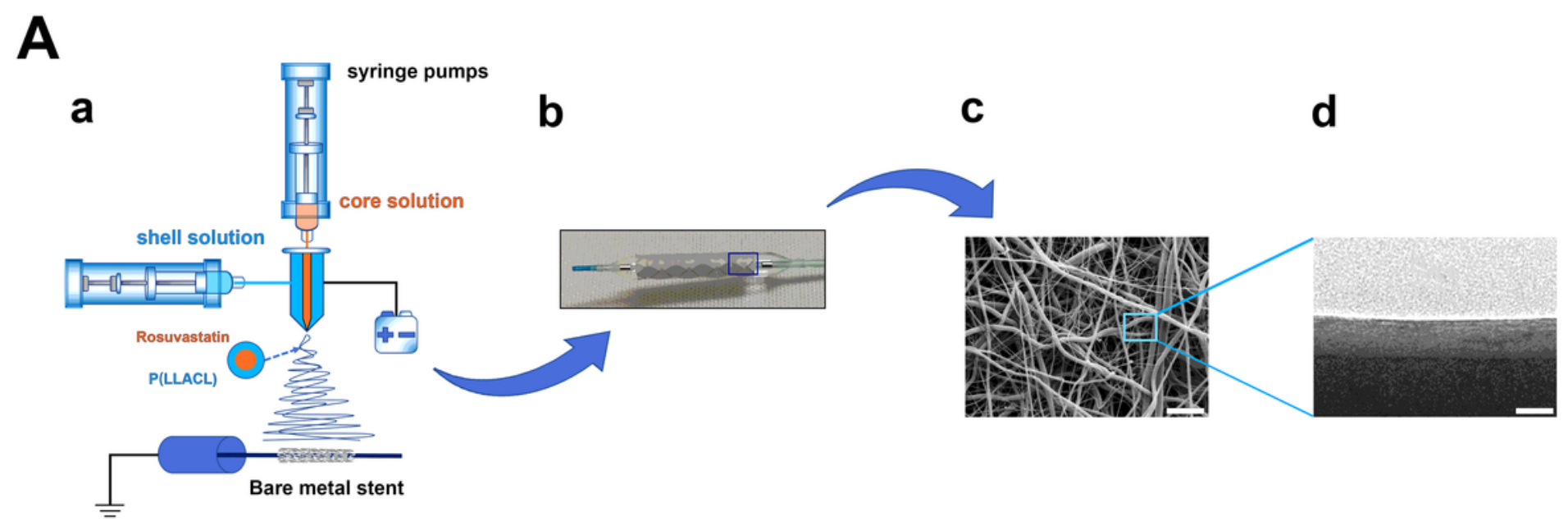

B

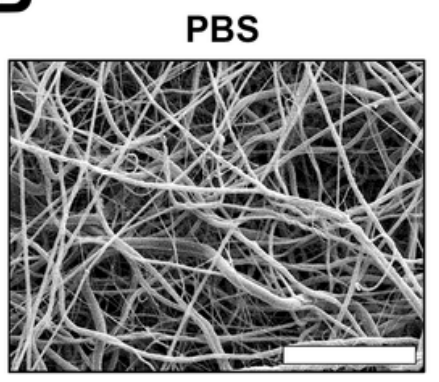

Standard deviation $=315 \mathrm{~nm}$ Mean diameter $=1525 \mathrm{~nm}$

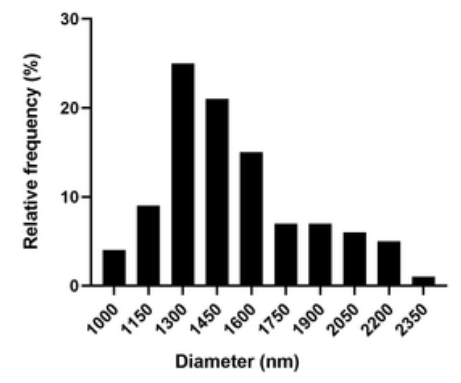

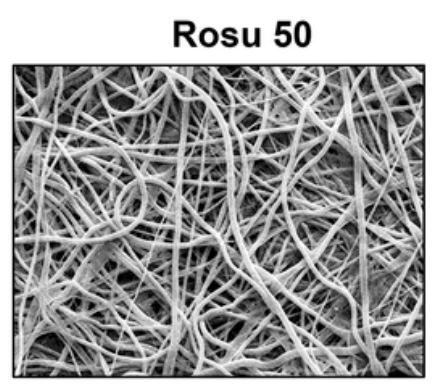

Standard deviation $=282 \mathrm{~nm}$

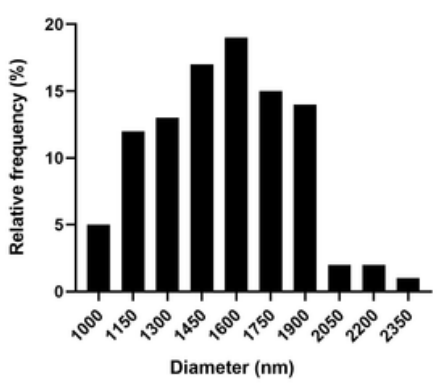

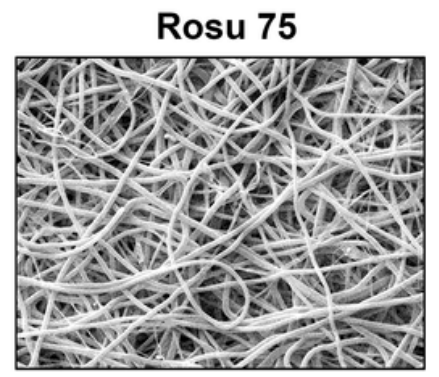

Standard deviation $=294 \mathrm{~nm}$

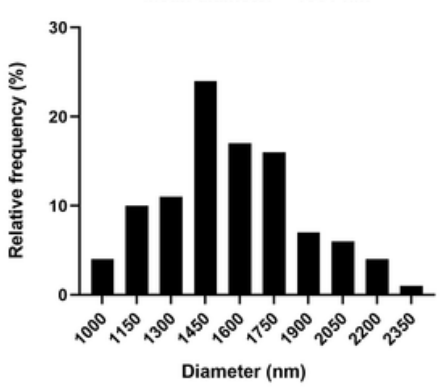

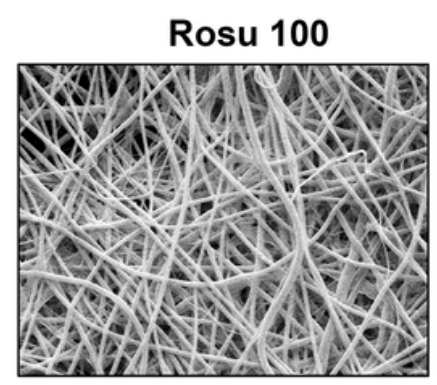

Standard deviation $=322 \mathrm{~nm}$ Mean diameter $=1543 \mathrm{~nm}$

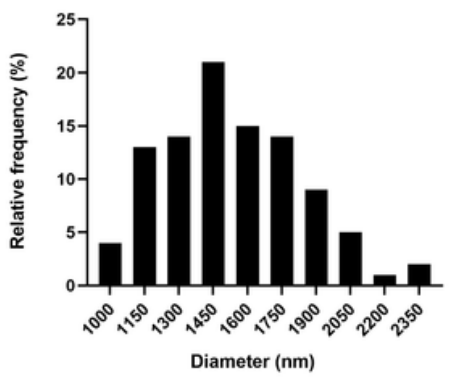

\section{Figure 1}

Nanofiber characterizations and mechanical properties. (A) Characteristics of nanofiber-covered stent: (a) Schematic diagram of stent graft fabrication, (b) Nanofiber-covered stent, (c) SEM images of nanofiber mats. Scale bar represents $10 \mu \mathrm{m}$, (d) TEM image of core-shell structure. Scale bar represents $20 \mathrm{~nm}$ (B) Diameter distribution of nanofiber mats. Scale bar represents $25 \mu \mathrm{m}$. 

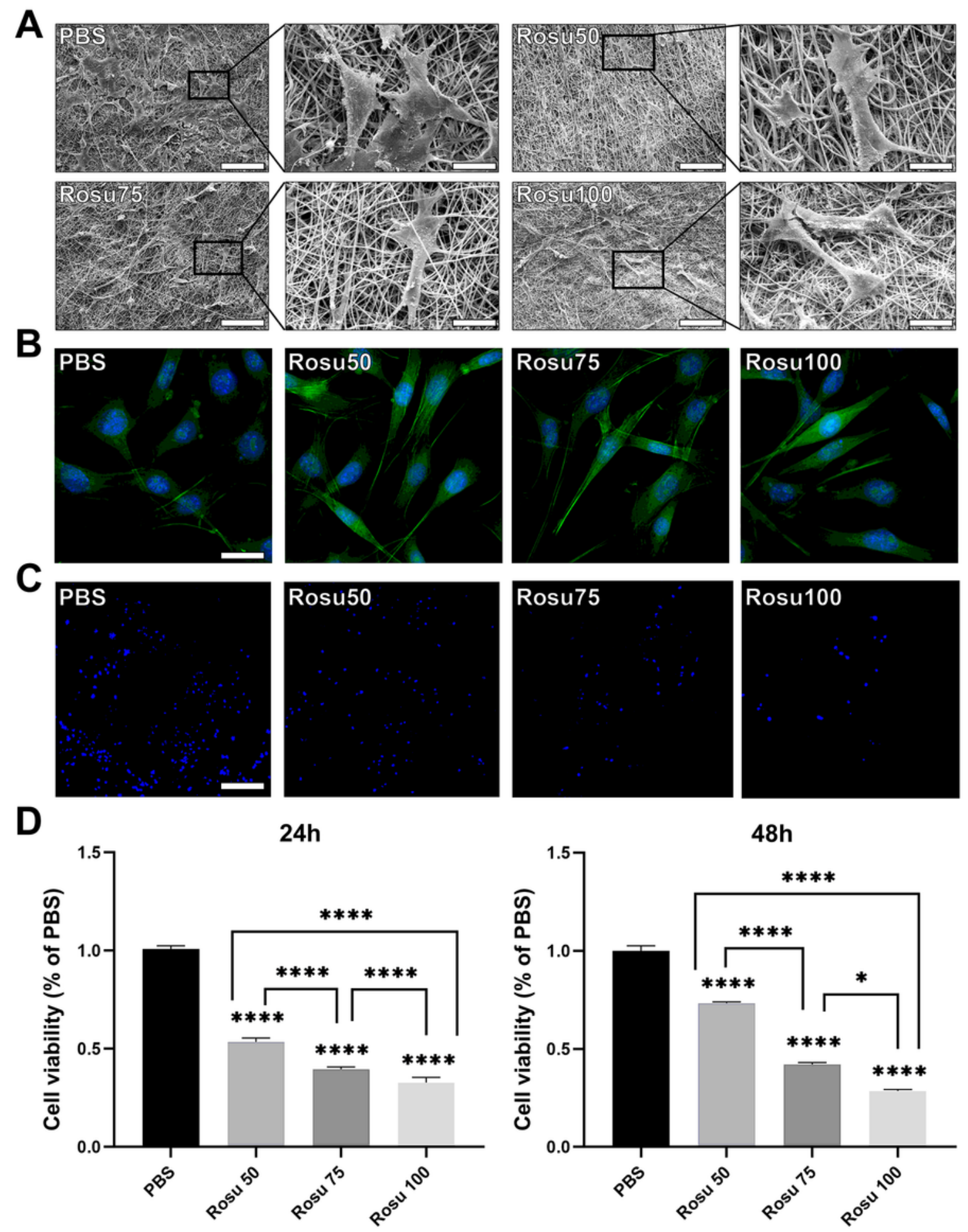

Figure 2

Viability and morphology of attached SMCs (A) SEM images of synthetic SMCs attached to PBS, Rosu 50, Rosu 75, and Rosu 100 nanofiber mats. Scale bar represents $100 \mu \mathrm{m}$. Corresponding magnified image. Scale bar represents $25 \mu \mathrm{m}$. (B) Phalloidin-labeled SMCs attached to nanofiber mats. Scale bar represents $30 \mu \mathrm{m}$. (C) Hoechst-33342-labeled SMCs attached to nanofiber mats. Scale bar represents 150 $\mu \mathrm{m}$. (D) Bar graph showing viabilities of SMCs attached to nanofiber mats after 24 and $48 \mathrm{~h}$. 

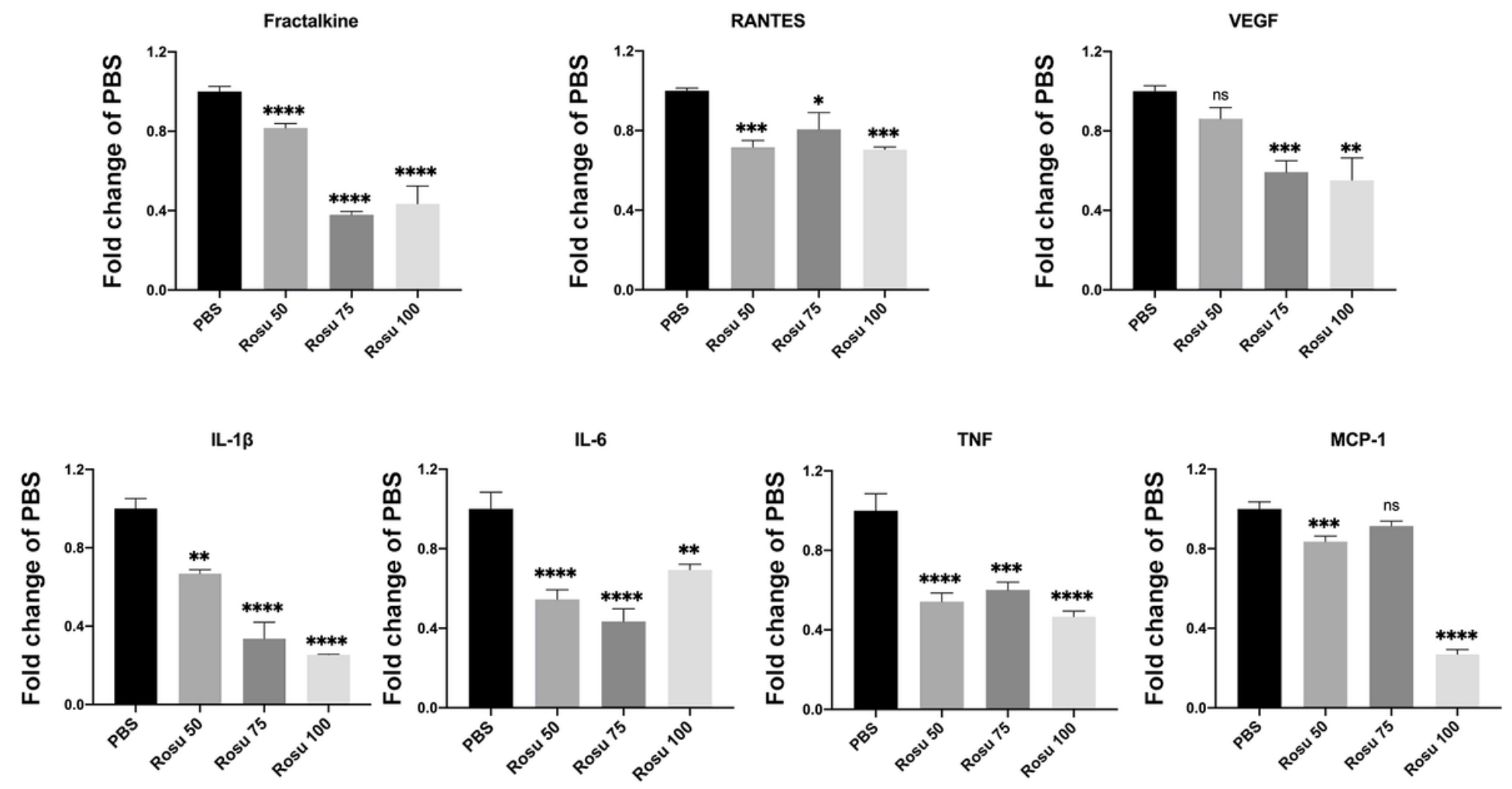

Figure 3

Cytokine secretions of attached SMCs. Bar graph showing levels of inflammatory factors secreted by SMCs attached to nanofiber mats, as determined by MILLIPLEX® MAP. Data are presented as mean \pm SD; $\mathrm{n}=3$ group. ${ }^{\star} \mathrm{p}<0.05,{ }^{\star \star \star *} \mathrm{p}<0.0001$. 


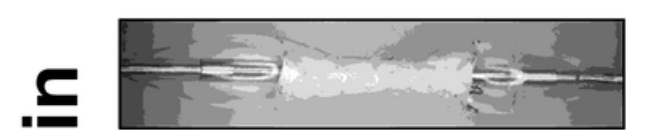

6 bar

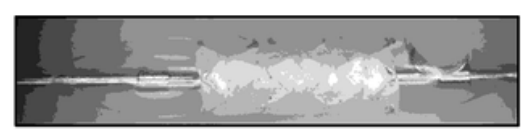

9 bar

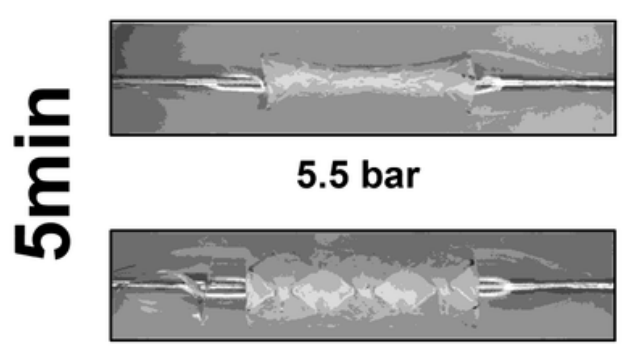

9.5 bar

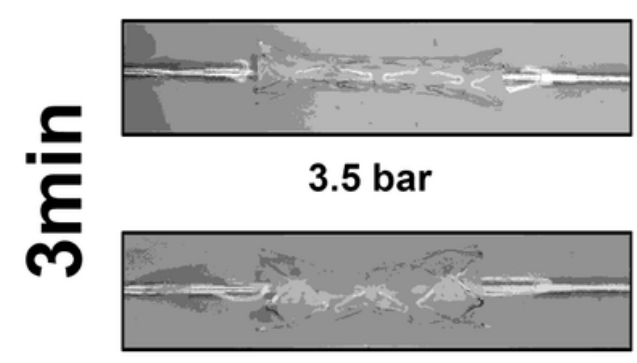

4.5 bar

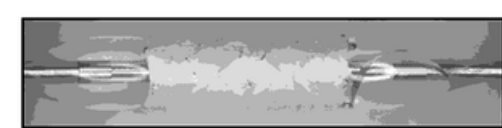

6.5 bar

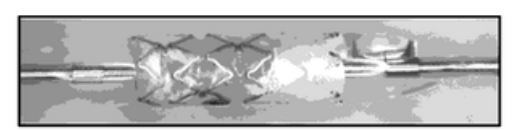

9.5 bar

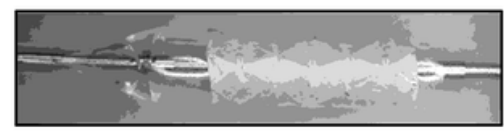

6 bar

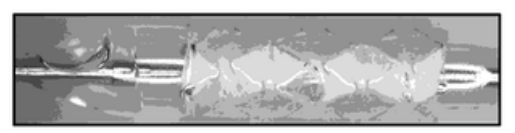

10 bar

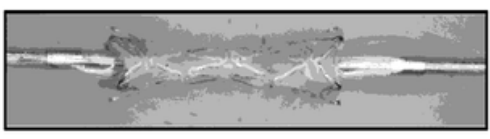

4 bar

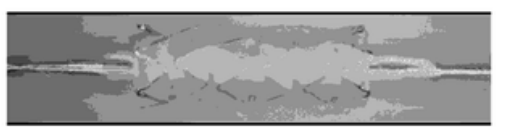

5.5 bar
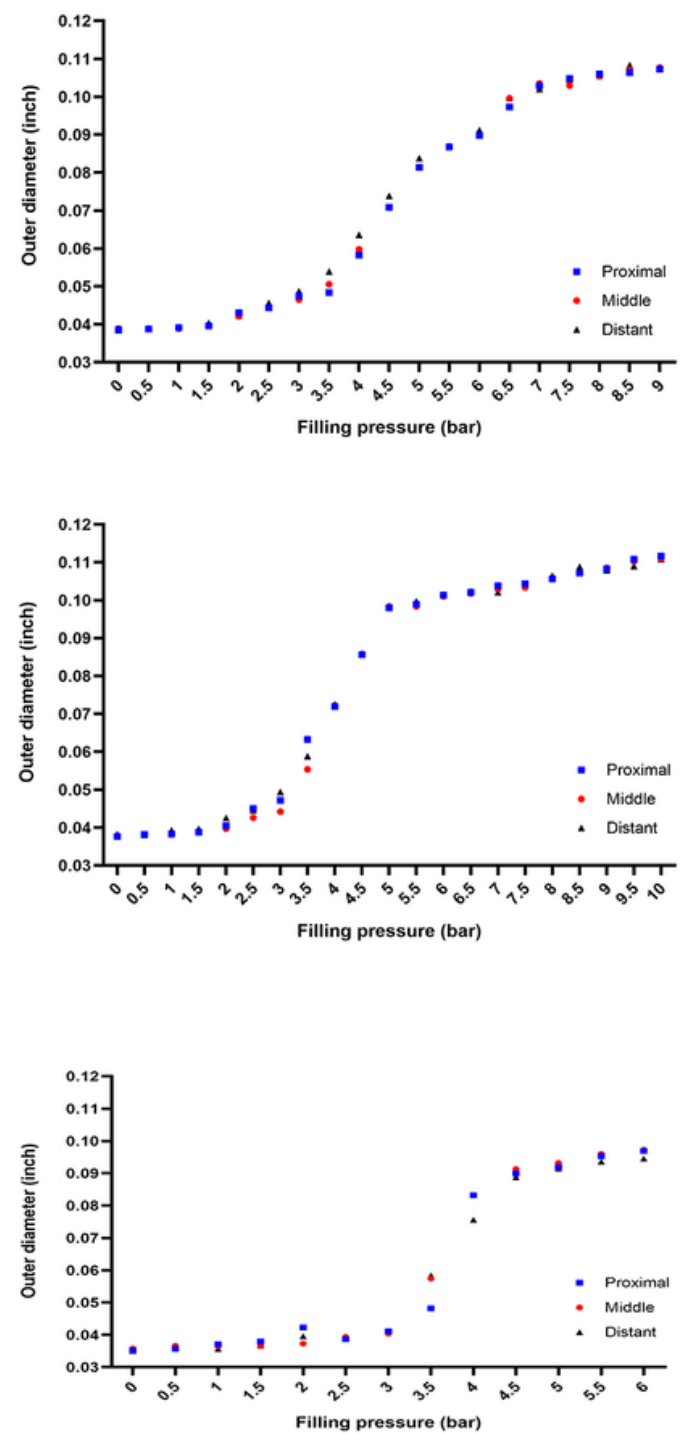

\section{Figure 4}

Images and corresponding scatter charts for balloon-expansion experiments on covered stents fabricated with nanofiber scaffolds spun for 10, 5, and 3 min. 
A
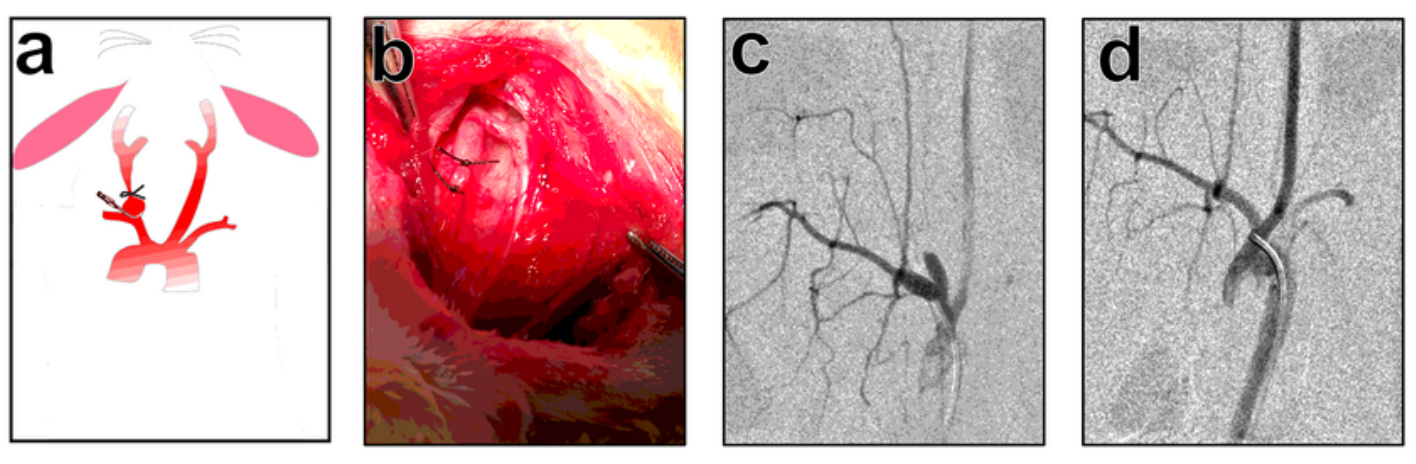

B
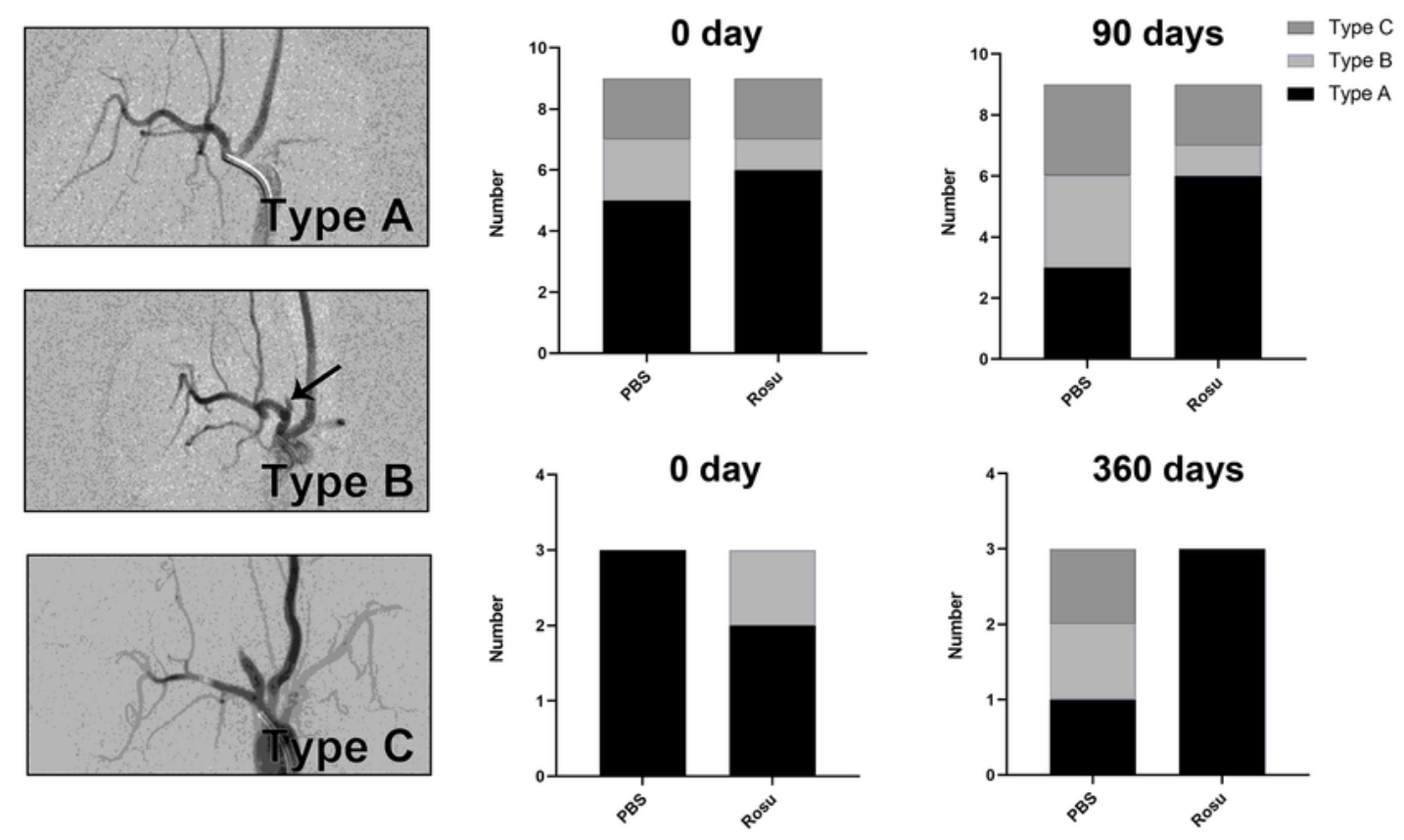

C
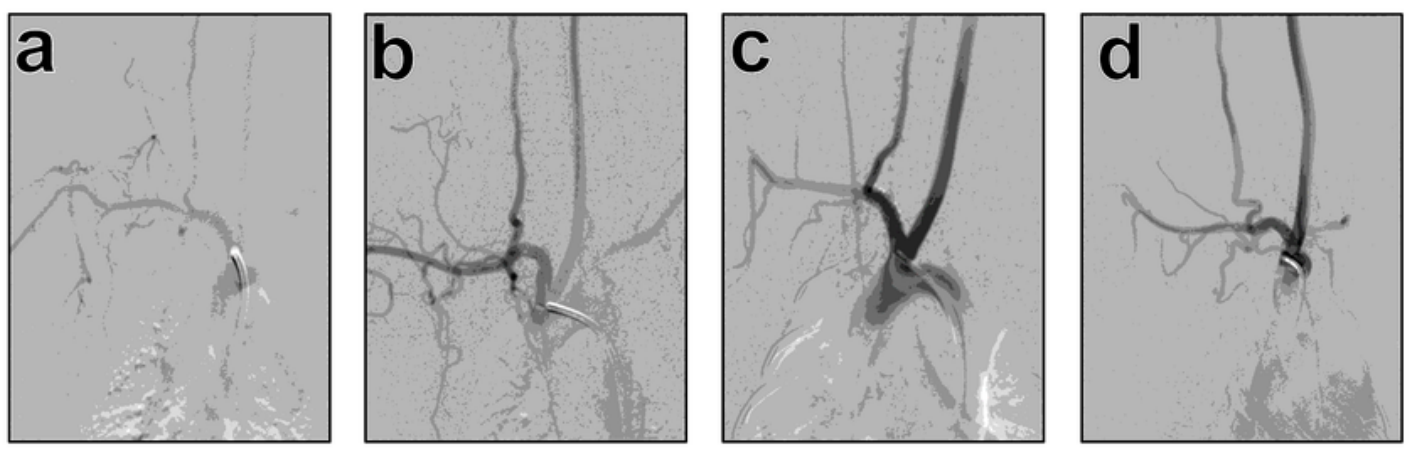

\section{Figure 5}

Rabbit-aneurysm initiation and short- and long-term follow-ups. (A) Initiation of rabbit-aneurysm model and stent implantation: (a) Schematic diagram of aneurysm initiation. (b) Photograph of induced aneurysm. (c) Angiography of aneurysm after $30 \mathrm{~d}$. (d) Angiography of aneurysm occlusion after stent implantation. (B) Angiography illustrations of types A, B, and C at follow-up. Bar graph showing number of different types in PBS and Rosu 100 groups immediately after implantation and at 3-and 12-month 
follow-ups. (C) Angiography of parent artery at (a) and (b) 3-and (c) and (d) 12-month follow-ups of PBS and Rosu 100 groups.

A
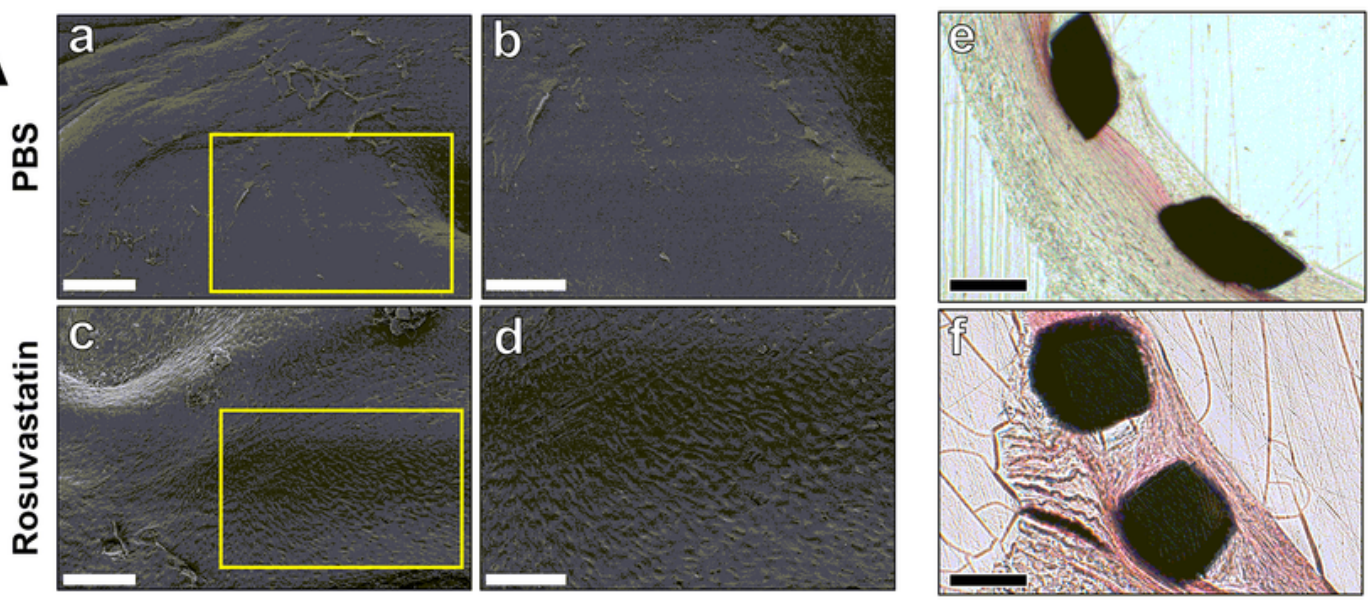

B
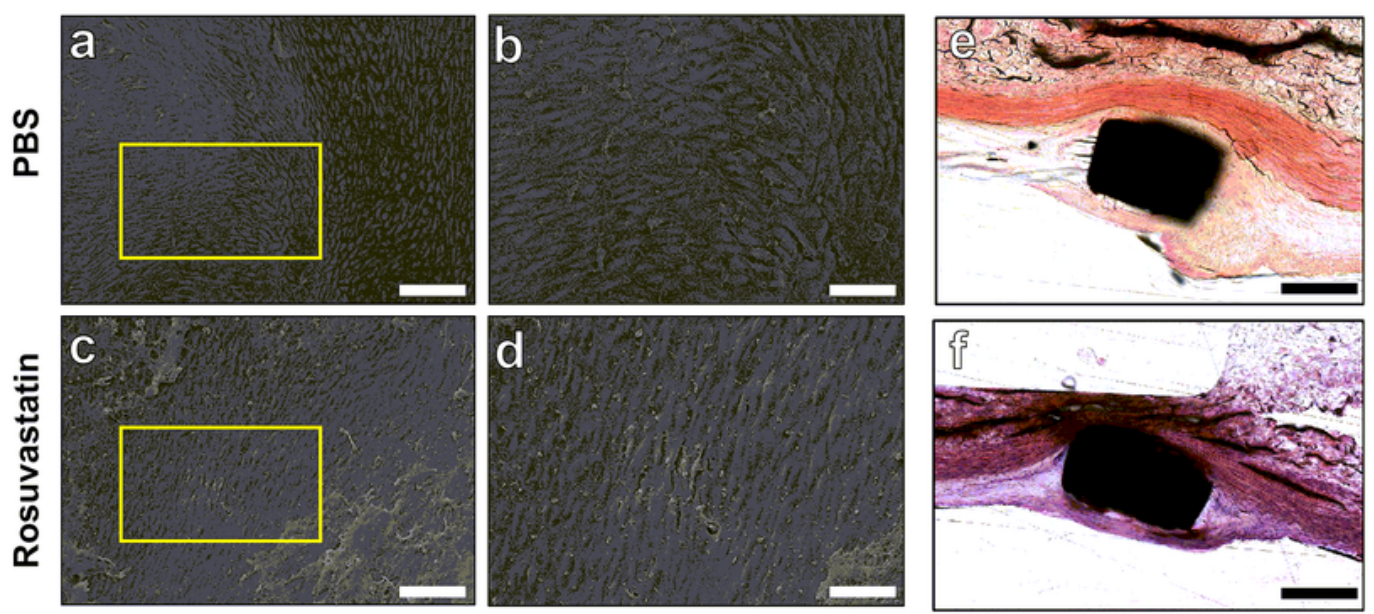

C
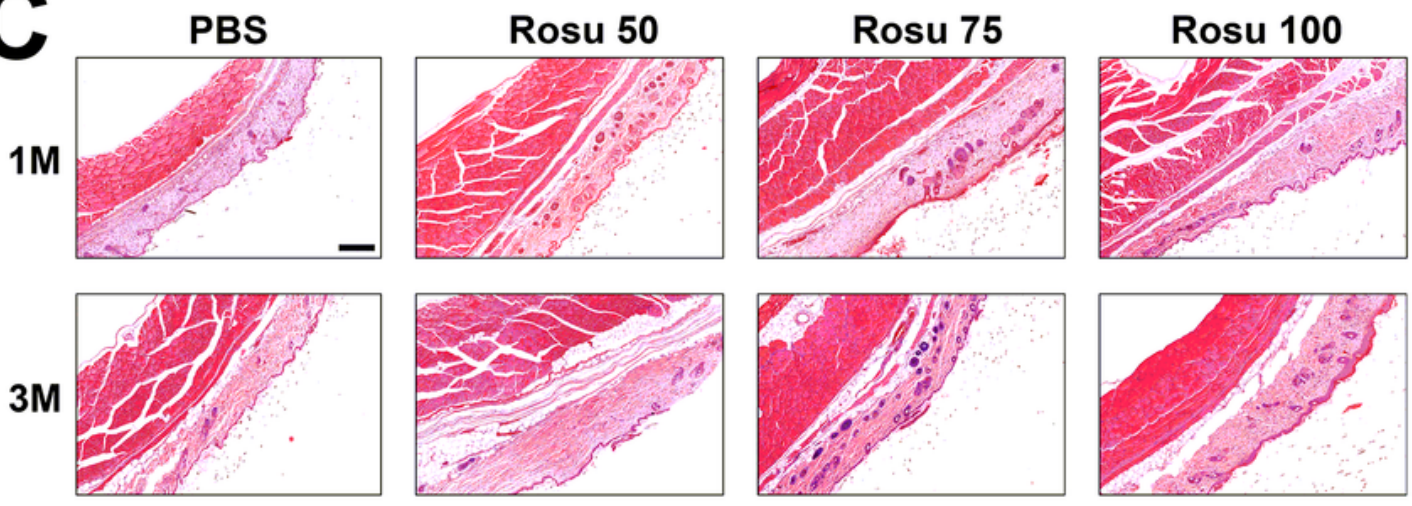

\section{Figure 6}

SEM, histology, and toxicity of nanofiber scaffold mats. (A) SEM and H\&E-stained vascular-section images showing endothelialization of covered stent at 3 months. (a, c) Scale bar represents $150 \mu \mathrm{m}$. (b, d, e, f) Scale bar represents $100 \mu \mathrm{m}$. (B) SEM and H\&E-stained vascular-section images showing 
endothelialization of covered stent at 12 months. (a, c) Scale bar represents $150 \mu \mathrm{m}$. (b, d, e, f) Scale bar represents $100 \mu \mathrm{m}$. (C) H\&E-stained vascular-section images showing effects of PBS, Rosu 50, Rosu 75, and Rosu 100 nanofiber mats implanted under abdominal subcutaneous tissue for 1 and 3 months.

Scale bar represents $250 \mu \mathrm{m}$.

A
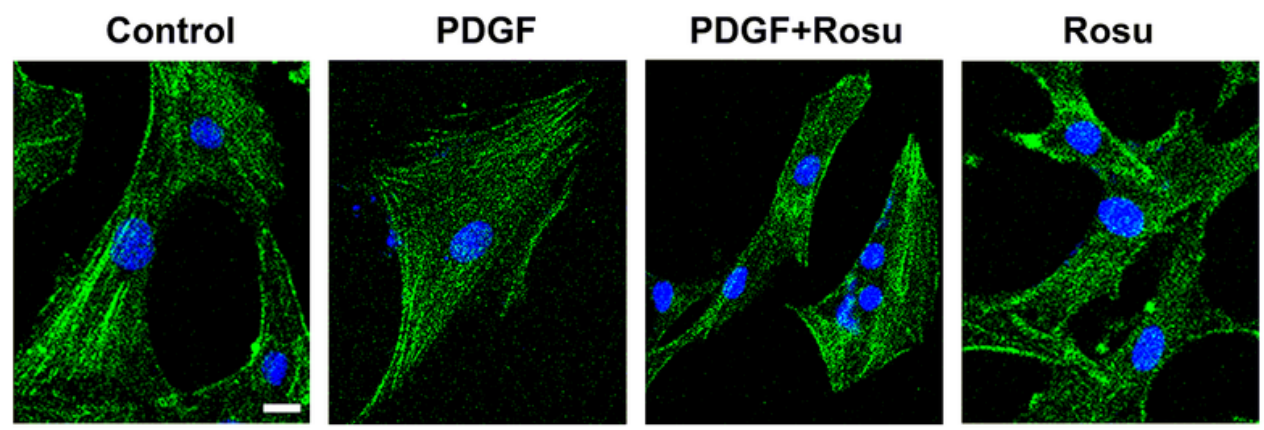

B
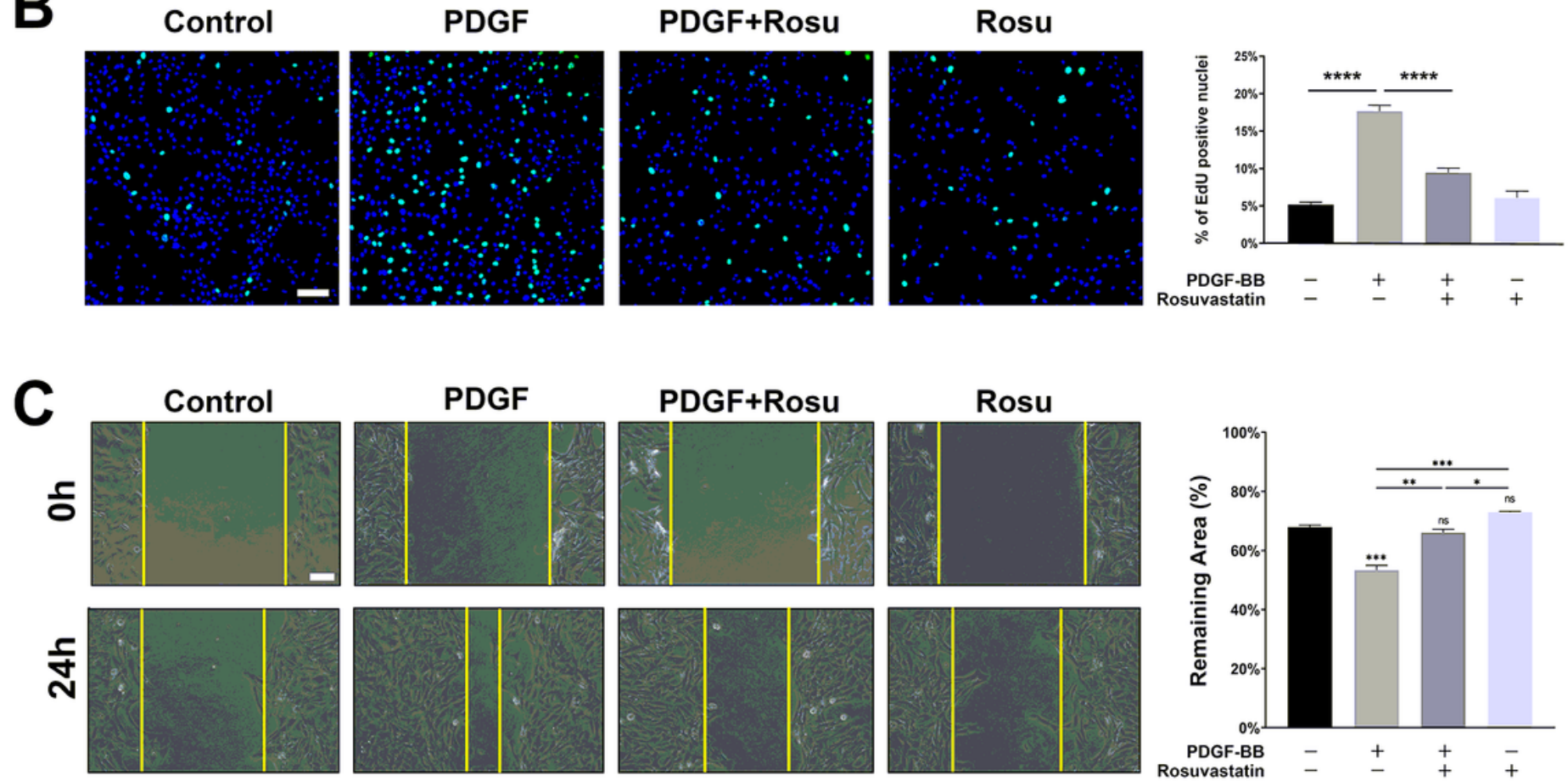

D
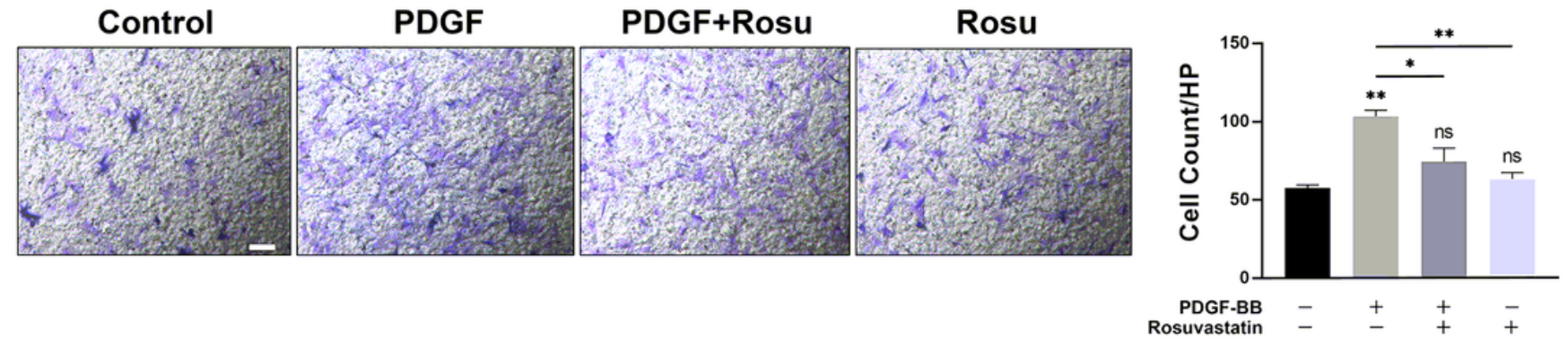

Figure 7

Cell morphology, viability, and function of PDGF-BB- and rosuvastatin-treated SMCs. (A) Cell morphology of control, PDGF, PDGF+Rosu, and Rosu groups. Scale bar represents $20 \mu \mathrm{m}$. (B) Cell proliferation rate of 
control, PDGF, PDGF+Rosu, and Rosu groups. Scale bar represents $100 \mu \mathrm{m}$. Bar graph showing cell proliferation rate (\%). Data are presented as mean $\pm S D ; n=3$ group. ${ }^{\star \star \star \star} p<0.0001$. (C) Wound healing assays and corresponding representative images of SMC migration in control, PDGF, PDGF+Rosu, and Rosu groups in scratch assay. Scale bar represents $100 \mu \mathrm{m}$. Data are presented as mean \pm SD; $\mathrm{n}=3$ group. ${ }^{\star} p<0.05,{ }^{*} p<0.01, * \star \star p<0.001$. (D) Transwell assays and corresponding representative images of crystal-violet-stained invasive cells in lower chamber. Scale bar represents $100 \mu \mathrm{m}$. Data are presented as mean $\pm S D ; n=3$ group. ${ }^{*} p<0.05,{ }^{*} p<0.01$.

A
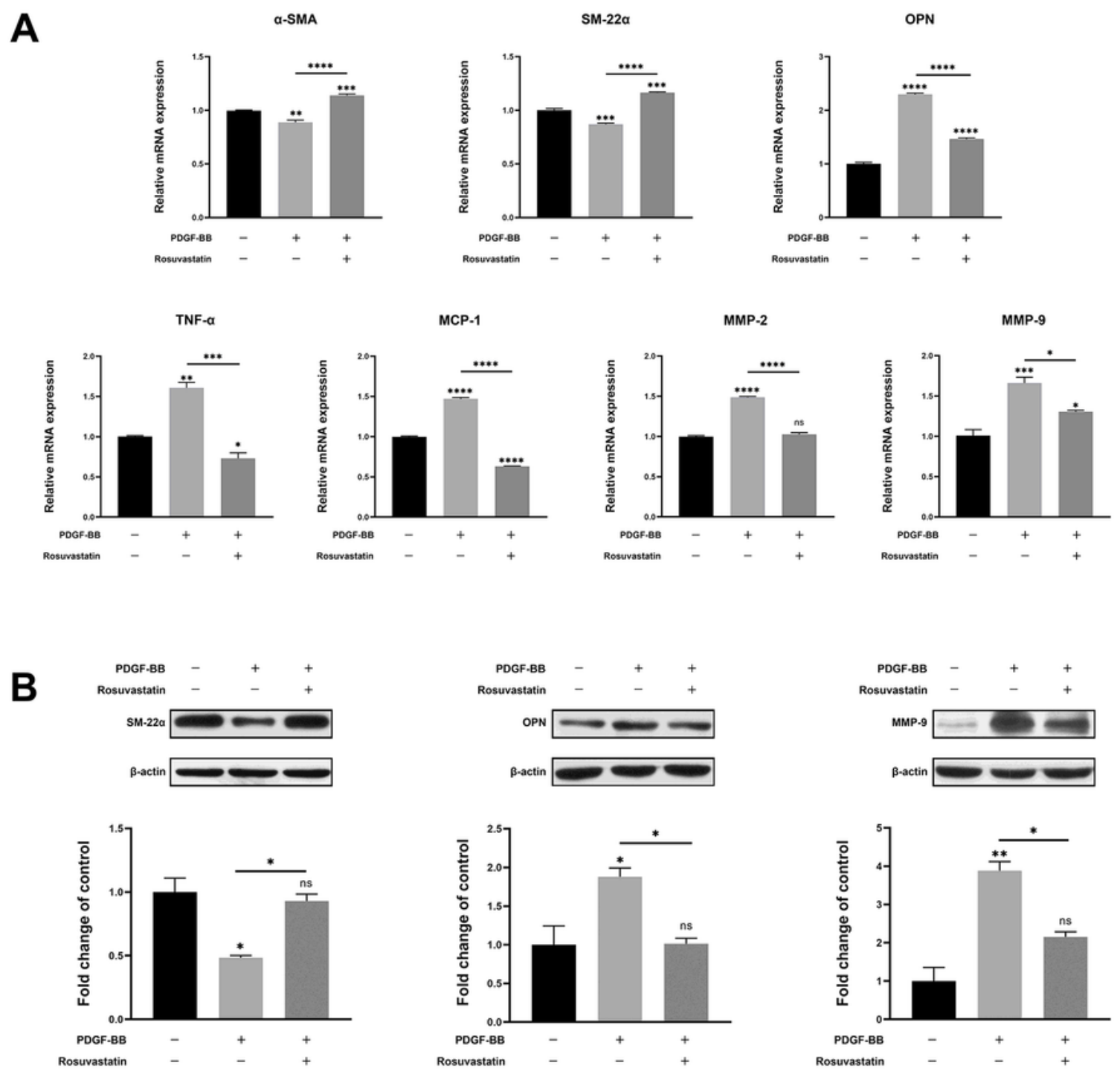

C
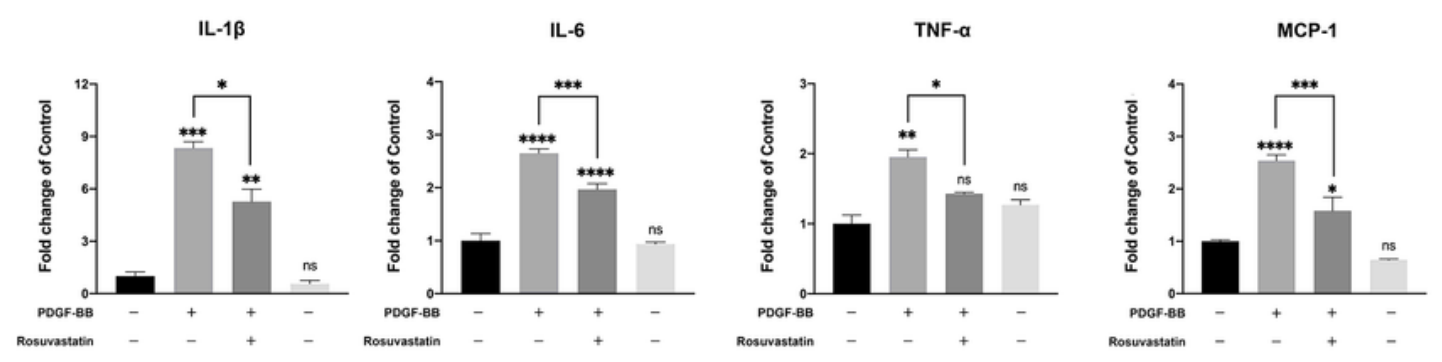


\section{Figure 8}

Effects of PDGF-BB- and rosuvastatin-treated SMCs on phenotype markers and inflammatory cytokines. (A) Fold changes for mRNA levels of a-SMA, SM22-a, OPN, and inflammatory cytokines. Data are

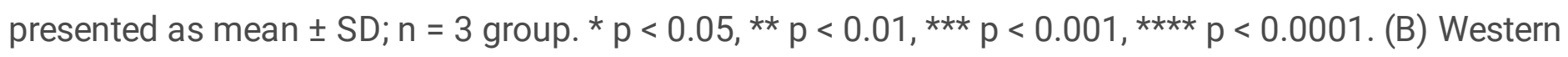
blot analysis of SM22-a, OPN, and MMP-9. Data are presented as mean \pm SD; $n=3$ group. ${ }^{\star} p<0.05$, ${ }^{* *} p$ $<0.01$. (C) Inflammatory cytokines analyzed by MILLIPLEX® MAP Rat CVD Panel. Data are presented as

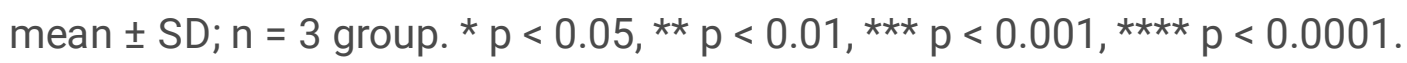

\section{Supplementary Files}

This is a list of supplementary files associated with this preprint. Click to download.

- 2020.11.07SupplementaryFile1.0.docx

- FigureGraphicalabstract.tif 